\title{
Relaciones de poder en cuatro obras de la literatura kurda contemporánea*
}

\author{
FREDY ALBERTO VELÁSQUEZ BARÓN ** \\ JUAN CARLOS GARCÍA PERILLA ***
}

Artículo de investigación sobre las relaciones de poder entre los kurdos y los representantes de los Estados que atraviesan Kurdistán, desarrolladas en cuatro obras literarias contemporáneas.

Recibido: 18 de febrero de 2019 - Evaluado: 10 de marzo del 2020 - Aceptado: 2 de abril del 2020

Citar como: Velásquez Barón, F. A. y García Perilla, J. C. (2020). Relaciones de poder en cuatro obras de la literatura kurda contemporánea. Hallazgos, 17(34), 79-120. DoI: https://doi. org/10.15332/2422409X.5018

Este artículo es producto de la investigación titulada "El Estado Islámico: catalizador del irredentismo kurdo y la reconstrucción del Medio Oriente”, desarrollada en 2018 y registrada con el código INV-EEs 2087 de la Universidad Militar Nueva Granada, Colombia.

** Magíster en Evaluación y Aseguramiento de la Calidad de la Educación de la Universidad Externado de Colombia. Auxiliar de investigación de la Universidad Militar Nueva Granada, Colombia.

Correo electrónico: favelasquezb@hotmail.com

ORCID: 0000-0003-2764-9355

*** Magíster en Seguridad y Defensa Nacionales de la Escuela Superior de Guerra. Docente investigador del Programa de Relaciones Internacionales y Estudios Políticos de la Universidad Militar Nueva Granada, Colombia.

Correo electrónico: juan.garcia@unimilitar.edu.co

ORCID: 0000-0002-9620-4635 


\section{Resumen}

El nacionalismo kurdo es un fenómeno de relevancia mundial que ha cobrado mayor notoriedad desde hace quince años, con la invasión de Irak por parte de Estados Unidos (2003) y el empoderamiento del Estado Islámico. En este contexto, los kurdos han ganado algunas reivindicaciones con la conformación de regiones autónomas en Irak y Siria. En este artículo se exploran y caracterizan desde la literatura las relaciones de poder tejidas entre los kurdos y los países que tienen soberanía sobre su territorio, mediante el análisis de las novelas El halcón (1997), de Yasar Kemal, novelista turco; Las plumas (1992), del poeta y novelista sirio Salim Barakat; Tierra de frontera (2001), de Sherko Fatah, escritor alemán de origen kurdo-iraquí; y el libro de cuentos El loco de la plaza Libertad (2016), de Hassan Blasim, cineasta y escritor iraquí. Para estudiar la relación de poder entre los kurdos y los Estados donde viven se formularon y desarrollaron tres categorías de análisis: cultura kurda, con base en el concepto de habitus de Pierre Bourdieu; relación entre los kurdos y los Estados que atraviesan Kurdistán, con sustento en la teoría del poder de Michel Foucault; y la subversión como intento independentista, según el concepto de línea de fuga de Gilles Deleuze y Félix Guattari.

Palabras clave: habitus, Kurdistán, líneas de fuga, literatura kurda, relaciones de poder. 


\section{Power relations in four works of contemporary Kurdish literature} Abstract

Kurdish nationalism is a phenomenon of global relevance that has gained greater notoriety since fifteen years ago, with the invasion of Iraq by the United States (2003) and the empowerment of the Islamic State. In this context, the Kurds have won some demands with the formation of autonomous regions in Iraq and Syria. This article explores and characterizes from literature the power relations woven between the Kurds and the countries that have sovereignty over their territory, through the analysis of the novels The hawk (1997), by Yasar Kemal, a Turkish novelist; The feathers (1992), by Syrian poet and novelist Salim Barakat; Borderland (2001), by Sherko Fatah, a German writer of Kurdish-Iraqi origin; and the storybook The Madman of Freedom Square (2016), by Hassan Blasim, an Iraqi filmmaker and writer. To study the power relations between the Kurds and the States where they live, three categories of analysis were made and developed: Kurdish culture, based on Pierre Bourdieu's concept of habitus; relations between the Kurds and the states that cross Kurdistan, based on Michel Foucault's theory of power; and subversion as an attempt at independence, according to the concept of the line of flight of Gilles Deleuze and Félix Guattari.

Keywords: habitus, Kurdistan, lines of flight, Kurdish literature, power relations.

\section{Relações de poder em quatro obras da literatura curda contemporânea \\ Resumo}

O nacionalismo curdo é um fenômeno de relevância mundial que vem ganhando atenção há 15 anos, com a invasão do Iraque por parte dos Estados Unidos (2003) e do empoderamento do Estado Islâmico. Nesse contexto, os curdos conquistaram algumas de suas reivindicações com a conformação de regiões autônomas no Iraque e na Síria. Neste artigo, são exploradas e caracterizadas, com base na literatura, as relações de poder entre os curdos e os países que têm soberania sobre seu território mediante a análise dos romances Memed, meu falcão (1997), de Yasar Kemal, romancista turco; As penas (1992), do poeta e romancista sírio Salim Barakat; Na região limitrofe (2001), de Sherko Fatah, escritor alemão de origem curdo-iraquiana, e o livro de contos O louco da praça da liberdade (2016), de Hassan Blasim, cineasta e escritor iraquiano. Para estudar a relação de poder entre os curdos e os Estados onde moram, são formuladas e desenvolvidas três categorias analíticas: cultura curda, com base no conceito de "habitus" de Pierre Bourdieu; relação entre os curdos e os Estados que cruzam o Curdistão, apoiada na teoria do poder de Michel Foucault, e a subversão como tentativa de independência, segundo o conceito de "linha de fuga", de Gilles Deleuze e Félix Guattari.

Palavras-chave: habitus, Curdistão, linhas de fuga, literatura curda, relações de poder. 


\section{Introducción}

Kurdistán es una región del Oriente Próximo entre Turquía, Siria, Irak e Irán, con la que la comunidad internacional ha mantenido históricamente relaciones ambiguas marcadas por su importancia geoestratégica. Por una parte, algunas facciones kurdas son reconocidas como un actor mundial relevante del cual se sirve a través de milicias kurdas para repeler amenazas terroristas como la expansión del Estado Islámico. Además, aprovecha sus recursos naturales: gas, petróleo, agua y agro. No obstante, por otro lado, no le permite conformarse como Estado kurdo, a pesar de que los kurdos, descendientes de los medos, se asentaron en este territorio aproximadamente hace 4000 años (Martorell, 2016). Las luchas por el poder político, económico y religioso en Kurdistán han provocado sobre la población de origen kurdo todo tipo de vejámenes, negación de su nacionalidad y de sus derechos civiles, ocultamiento cultural e, incluso, exterminio. Los kurdos viven la paradoja de ser tratados como extranjeros en la tierra que han habitado antes que los persas, árabes y turcos. En el presente artículo se exploran y caracterizan, a través de obras literarias, las relaciones de poder (Bourdieu, 2000; Foucault, 2016; Deleuze y Guattari, 2004; Balandier, 1990) —lazos sociales continuamente tensados por las relaciones de fuerza y dominación- tejidas entre los kurdos y los países que tienen soberanía sobre su territorio.

Estas relaciones de poder han sido representadas en la literatura kurda contemporánea, específicamente en novelas y cuentos donde se hallan interpretaciones vívidas de la particularidad que representa ser kurdo. La literatura kurda contemporánea refleja los contextos sociales en los que se han formado los escritores de origen kurdo, ofreciendo a los lectores occidentales una perspectiva narrativa del drama que padecen los kurdos. Esta literatura podría estudiarse en otras investigaciones en las que a través del análisis comparativo se relacione con literatura latinoamericana que reivindique cultural y socialmente a los pueblos autóctonos sometidos y absorbidos por Estados hegemónicos, como es el caso de la literatura zapatista mexicana del subcomandante Marcos, cuyos ensayos, discursos y relatos transmiten la cosmovisión y la crítica social de diferentes grupos indígenas mexicanos. También se puede relacionar con la literatura mapuche, la cual evolucionó interculturalmente, mostrando la experiencia cultural de este pueblo al interactuar con la sociedad chilena de origen español radicada en su territorio.

El pueblo kurdo conforma una etnia con casi cuarenta millones de integrantes, cuyo territorio (Kurdistán) se constituye en un espacio geográfico imaginario que incluye principalmente territorios de Turquía, Irak, Irán y Siria; ha sufrido, desde 
mediados del siglo xx, desplazamiento forzado, limpieza étnica, lingüicidio y genocidio. Sin embargo, en algunas coyunturas, las comunidades kurdas han tenido épocas de cooperación con los gobiernos de estos países, pero también momentos de rebelión y guerra (Bozarslan, 2014).

Después de la Primera Guerra Mundial, a través del tratado de Lausana de 1923, Kurdistán quedó divido dentro de las fronteras de los cuatro países en mención. Al ser un territorio rico en recursos naturales ha tenido que afrontar su maldición histórica: "asentarse en la noche de los tiempos en una zona del mundo que no ha dejado de adquirir importancia geoestratégica” (Martorell, 2016, p. 12), forjándose con esto la imposibilidad del pueblo kurdo de establecer soberanía en su nación.

La selección de las obras abordadas ha tenido en cuenta que sus autores sean de origen kurdo, que las historias se enmarquen en los siglos xx y xxI, y que estén traducidas al castellano, lo que facilita su acceso en Hispanoamérica. Las siguientes son las novelas estudiadas: El halcón (1997), de Yasar Kemal, novelista turco; Las plumas (1992), del poeta y novelista sirio Salim Barakat; Tierra de frontera (2001), de Sherko Fatah, escritor alemán de origen kurdo-iraquí; y el libro de cuentos El loco de la plaza Libertad (2016), de Hassan Blasim, cineasta y escritor iraquí.

En las anteriores obras predomina el realismo como estilo literario, que permite abordar directamente los contextos de los personajes kurdos, con sus particularidades dramáticas bastante marcadas por su condición de habitantes de países donde históricamente han sido considerados como ciudadanos de segunda categoría, con menos derechos civiles o sin ellos: "en Siria y Turquía se niega su existencia y en Irak e Irán queda limitada a solo una parte de las tierras que habitan” (Martorell, 2016, p. 12). No obstante, la novela Las plumas (1992) en algunos apartados combina el estilo realista con elementos fantásticos, de manera similar al realismo mágico latinoamericano.

Las fronteras entre países como límites geopolíticos conforman un punto común en estas obras, produciendo una paradoja, puesto que, si bien separan a Irak, Irán, Turquía y Siria, se encuentran dentro de Kurdistán, dividiéndolo artificialmente, bajo la perspectiva de la población kurda, y complejizando su tránsito de forma exponencial. Las fronteras representan para los kurdos la oportunidad de escapar de la opresión de los países donde viven y también son el símbolo del arrinconamiento al que los Estados los someten, empujándolos a afrontar experiencias extremas hasta el límite entre la vida y la muerte, el cual puede materializarse al pisar una mina en las dunas entre Irak y Turquía o al sucumbir en las aguas de uno de los ríos que separan a Siria de Turquía. 
Otro elemento común en las obras estudiadas es el ánimo independentista que embarga a algunos de los personajes, involucrándolos con intentos, en su mayoría frustrados, de rebelión ante la marginación y violencia que los distintos Estados, por medio de terratenientes, militares y terroristas, ejercen sobre los kurdos e incluso sobre su propia población. La opresión a la que los países soberanos someten al pueblo kurdo cruza permanentemente las historias de las obras literarias kurdas, con lo cual reflejan el drama que vive esta etnia a causa del esfuerzo por la reafirmación de la soberanía de los países que tienden sus fronteras sobre Kurdistán.

El tema político e histórico de la relación de poder entre los kurdos y los Estados donde están instalados también atraviesa el campo literario. Así se comprobó al estudiar las obras literarias ya mencionadas. Después de esta constatación se requirió identificar las líneas temáticas que se repetían de una obra a otra y que podían dar una perspectiva humanizada del problema de las relaciones de poder kurdas, dado que esta literatura acude a experiencias y percepciones de la realidad de autores kurdos, quienes encuentran en la escritura la manera de conjurar y hacer explícita la opresión a la que han sido sometidos como etnia.

Este compromiso e identidad que los escritores kurdos seleccionados en este trabajo sostienen los inscribe en la línea de los autores que se asumen como testigos sociales, con las consecuencias que ello les puede traer por parte de los Estados, puesto que reclaman justicia, libertad y respeto por las personas. Este tipo de escritor lo expone y asume el novelista, ensayista, pintor y doctor en física argentino Ernesto Sabato, al identificarse con la clasificación del oficio del escritor que hace el novelista y filósofo francés Albert Camus; ambos escritores profundamente impactados por las guerras mundiales, de manera análoga a los escritores kurdos que han sido marcados por la continua violencia que los Estados instalados sobre Kurdistán imponen a su etnia. El escritor como testigo tiene la siguiente impronta:

Como señaló Camus: “Uno no puede ponerse del lado de quienes hacen la historia, sino al servicio de quienes la padecen”. El escritor debe ser un testigo insobornable de su tiempo, con coraje para decir la verdad, y levantarse contra todo oficialismo que, enceguecido por sus intereses, pierde de vista la sacralidad de la persona humana. (Sabato, 2011, p. 57)

En concordancia con el anterior planteamiento, se evidenció cómo todos los autores tratados en esta investigación abordan las condiciones culturales, socioeconómicas y civiles kurdas, las cuales configuran sus relaciones con los países que habitan (habitus; Bourdieu, 1990, 2000), provocando dramas y expectativas 
independentistas. Esta relación de poder entre los kurdos y los Estados donde viven se estudia aquí a través de categorías de análisis que se desprenden de los temas más frecuentes tratados en las obras literarias, los cuales se relacionan con las problemáticas históricas y políticas kurdas.

Las categorías de análisis son: cultura kurda, la cual permite identificar la configuración jerárquica de las relaciones cotidianas dentro de las familias kurdas y sus comunidades; luego se pasa a la categoría relación entre los kurdos y los Estados que atraviesan Kurdistán, en la que se hace un acercamiento al rol público que desempeñan los kurdos y a las relaciones de poder que sostienen con los agentes encargados de ostentar y ejecutar el poder de los Estados donde se instalan; y, por último, se formuló la categoría la subversión como intento independentista, mediante la cual se exploran los personajes que expresan su disenso (línea de fuga) con las jerarquías de poder familiares, comunitarias, pero sobre todo políticas, por medio de intentos de confrontación física y política con los representantes del poder detentado contra los kurdos.

Este conjunto de categorías, deducidas de la frecuencia con que se trataron sus temas subyacentes (costumbres, jerarquías, relaciones de poder, entre otros), articulado, a su vez, con la problemática del nacionalismo kurdo como intento independentista, permite dar una perspectiva literaria a las relaciones de poder que se ejercen sobre la población kurda, las cuales constituyen el drama de millones de kurdos que no tienen la fuerza para hacer oír sus voces en la cultura occidental.

En la categoría cultura kurda se recurre a la teoría sociológica del filósofo francés Pierre Bourdieu (1990, 2000), quien aporta los conceptos de campo, capital y habitus, los cuales permiten caracterizar las relaciones de poder dentro de la organización familiar, a través de los distintos capitales (cultural, económico y social), y de los roles que desempeñan los kurdos en los ámbitos familiar y comunitario.

En la categoría relación entre los kurdos y los Estados que cruzan Kurdistán, a través de la teoría del poder del filósofo Michel Foucault (2016), se identifica el rol público que desempeñan los kurdos en sus sociedades y cómo los agentes representantes de los diferentes Estados se encargan de reafirmarles un lugar en la jerarquía social. Esto se evidencia a través de discursos (violencia simbólica) y del ejercicio de la fuerza, que generalmente lleva la acción de las novelas al escenario de las fronteras políticas entre Turquía, Irak, Irán y Siria, y a los accidentes geográficos más agrestes e inhóspitos; escenografías cargadas de simbolismo, puesto que representan la impotencia que los autores observan ante la imposibilidad de que Kurdistán sea un territorio plenamente soberano.

Por último, la categoría subversión como intento independentista, con base en el concepto de líneas de fuga de Gilles Deleuze y Félix Guattari (2004), se centra en el 
análisis de los personajes que, por motivaciones personales, familiares o sociales, en las que subyace un patrimonio histórico milenario que abarca continuas luchas internas y territoriales, deciden encarar la opresión y por ello sufren consecuencias, en su mayoría fatales, que reivindican el poderío social y militar de los países que cruzan Kurdistán.

A continuación, se presenta una breve descripción acerca de la configuración geográfica de Kurdistán, y las reseñas de los escritores y las obras literarias abordados. Luego se desarrollan en tres apartados independientes las categorías de análisis, a saber: cultura kurda, relación entre los kurdos y los Estados que cruzan Kurdistán, y subversión como intento independentista. Finalmente, se establecen las conclusiones.

El tratado de paz de Sèvres (Francia) se firmó el 10 de agosto de 1920 entre Turquía y las naciones aliadas de la Primera Guerra Mundial, excepto Rusia y Estados Unidos. En este tratado se dejaba al Imperio Otomano sin la mayor parte de su antiguo territorio, en Anatolia Oriental se creaba un Estado autónomo para los kurdos (Kurdistán), y varios distritos pasaban a Armenia. Sin embargo, este tratado no se ejecutó, puesto que a finales del siglo xix Turquía emprendió una campaña violenta para darle forma a la nación turca, en la cual buscó homogeneizar la cultura de sus habitantes a través de la turquicidad, el exterminio de los armenios y la expulsión de los griegos. Esta campaña nacionalista se concretó con la guerra de independencia turca que proclamó la República de Turquía en 1923, liderada por Mustafá Kemal Ataturk.

Inmediatamente después de la proclamación de la República Turca, se desconoció la consolidación de la región autónoma kurda, consignada en el tratado de Sèvres. Luego se firmó, el 24 de julio de 1923, entre los gobiernos de Grecia, Turquía y las naciones aliadas de la Primera Guerra Mundial, el tratado de paz de Lausana (Suiza), con el que se establecieron las fronteras de la Turquía moderna. Este tratado es considerado como una traición de Francia e Inglaterra a las minorías griega, armenia, kurda, asiria y yezidi frente al tratado de Sèvres, donde se plasmó la Doctrina Wilson acerca del derecho de autoderterminación de los pueblos (Martorell, 2016). Kurdistán quedó entonces dividido en cuatro partes entre Turquía, Irán, Irak y Siria.

El territorio total de Kurdistán suma cerca de $450000 \mathrm{~km}^{2}$ (figura 1); supera el tamaño medio de los países europeos. El Kurdistán turco tiene alrededor de $220000 \mathrm{~km}^{2}$ y 20 millones de habitantes; el Kurdistán iraní, aproximadamente $125000 \mathrm{~km}^{2}$ y 9 millones de habitantes; el Kurdistán iraquí, cerca de $76000 \mathrm{~km}^{2}$ y 5 millones de habitantes, y el Kurdistán sirio, $19000 \mathrm{~km}^{2}$, y un poco más de 2 millones de habitantes. En Europa y Estados Unidos, la diáspora kurda suma aproximadamente 2 millones de personas (Martorell, 2016; Torres, 2011). 


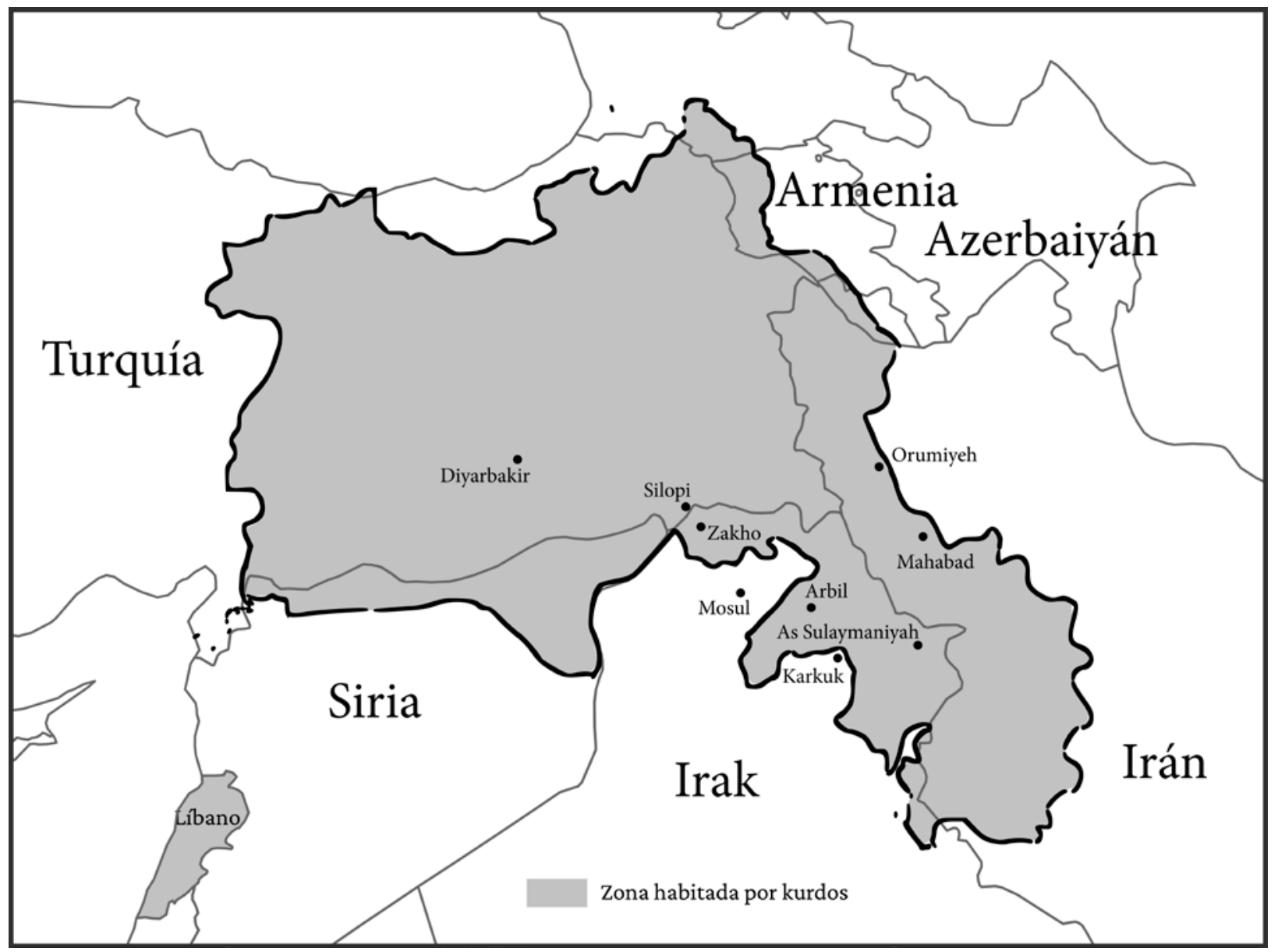

Figura 1. Mapa político actual de Kurdistán

Fuente: reelaborado a partir de CIA, 2019, con base en Martorell (2016, p. 142). Esta imagen se comparte con la licencia Creative Commons Attribution-Share Alike 4.0 International. 


\section{Escritores y obras literarias}

A continuación, se presentan los autores y las obras literarias estudiadas en este artículo.

\section{Yasar Kemal, El halcón}

Yasar Kemal (1923-2015) fue un novelista turco de origen kurdo, varias veces candidato al Premio Nobel de Literatura. Kemal se distinguió por su férreo compromiso político a favor de la población kurda de su país. "Estuvo encarcelado por defender los derechos del pueblo kurdo y llegó a autoexiliarse en Europa, pese a tener erigida, aún en vida, una estatua en el paseo marítimo de Istanbul” (Martorell, 2016, p. 39). Se hizo famoso con la publicación en 1955 de su primera novela, El halcón.

La novela El halcón se desarrolla entre 1925 y 1933 en Dikelin, una región llana del Kurdistán turco, al sureste de Turquía. El protagonista es Memed el Flaco, un joven de 11 años, que cierra el relato con 18 años de edad, quien vive con su mamá en Dikelin. La aldea de Memed aún tiene un sistema económico feudal, controlado por Abdi agá. Memed escapa de su aldea y se radica por un mes en la aldea de Kesme, donde Süleyman, un campesino que vive con su familia, decide emplearlo como cabrero. Sin embargo, Abdi agá se entera que Süleyman esconde a Memed y lo recupera.

Pasan siete años, Memed cumple 18 años y va con su amigo Mustafá a conocer la ciudad de Çukurova. Queda deslumbrado y quiere llevarse a su mamá y a su novia Hatçe a esta ciudad. No obstante, Abdi agá acuerda con los padres de Hatçe el matrimonio entre ella y su sobrino. En consecuencia, Memed escapa con Hatçe al campo. Hasta donde va Abdi agá con su sobrino y tienen un enfrentamiento armado con Memed, del cual salen heridos. Memed huye incorporándose, gracias a Süleyman, a la banda de Durdu el Loco. Sin embargo, después de algunos días en los que Memed demuestra su valentía, junto con Cabbar y el sargento Racep, decide abandonar la banda de Durdu, debido a la imprudencia y crueldad de este. Mientras tanto, Hatçe es encarcelada en Çukurova gracias a falsos testigos que la acusaron de asesinar al sobrino de Abdi agá. Allí comparte celda con una mujer llamada Iraz.

Memed se entera de que su madre ha muerto y busca a Abdi, quien se esconde en la aldea de Aktozlu, en casa de Hüseyin, el alcalde, pariente suyo. Allí Memed lo acecha para matarlo, pero logra escapar. Memed rescata a Hatçe y a Iraz, cuando las trasladaban para cambiarlas de cárcel. Ali Safa Bey envió al sargento Asim, al bandolero Ibrahim el Negro y a cincuenta voluntarios a perseguir a Memed. Esta situación sigue por meses. Hasta que Memed es acorralado en la montaña de Ali, donde nace su 
hijo en medio de un enfrentamiento. En uno de los combates muere Hatçe; por tanto, Iraz se encarga del bebé y se separa de Memed. Este último vuelve a su aldea el día en que empieza la amnistía a los bandoleros por la celebración del décimo aniversario de la república, lo cual ocurre en 1933. Pero decide ir a Çukurova a asesinar a Abdi agá. Lo consigue y entonces las cinco aldeas de la llanura de Dikelin quedan liberadas y Memed desaparece.

\section{Salim Barakat, Las plumas}

Salim Barakat es un poeta y novelista sirio de origen kurdo. Nació en 1951 en la ciudad de Qamishli, en el Kurdistán sirio. Vivió en Beirut, Líbano, varios años, y fue editor de la prestigiosa publicación $\mathrm{Al}$-Karmel, revista literaria de la Unión Palestina de Escritores. Escribe en árabe. Vivió una temporada en la isla de Chipre y desde 1999 vive en Suecia. Su literatura explora la cultura y la historia kurdas.

La novela Las plumas (1992) tiene dos partes, la primera se centra en Mem, el protagonista, y la segunda en Dino, hermano gemelo de Mem. La primera parte de la novela se desarrolla al inicio de la década de los setenta del siglo xx, en Qamishli. Mem es un joven de 27 años, que fue enviado a Chipre por su padre, Hamdi, con el encargo de reunirse con el Gran Hombre, sin ninguna instrucción para hacerlo, salvo que será cuidado por otros kurdos que viven allí. Mem vive en Chipre en una casa solo y ha decidido suicidarse. Antes de hacerlo rememora los últimos seis años que ha pasado incomunicado: no aprende el griego y habla lo mínimo con algunos kurdos en el restaurante donde almuerza. También hace un recuento de su adolescencia al lado de sus padres, su hermano gemelo y sus seis hermanas.

En la misma jornada donde sucede el primer capítulo, se trasladan a la vivienda al norte de la casa de Mem un hombre y una mujer envueltos en grandes abrigos. Mientras Mem sigue unas aves, llega a la ventana de la casa vecina y lo recibe el hombre del abrigo, quien lo llama por su nombre, Mem Azad, y le dice que debe seguir esperando al Gran Hombre y que la moraleja del asunto es que busque a un pájaro, aquel pájaro que le cambió las plumas por algo que Mem no sabe qué es. El hombre del abrigo le pide a Mem que haga ochenta mil copias manuscritas de la frase "Esos protestantes alemanes os mienten”, haciendo referencia a unos alemanes que antes de la Primera Guerra Mundial sacaron una revista llamada Kurdistán para los kurdos de Irán, con el objetivo de que se unieran al pacto germano-turco, con el cual finalmente Kurdistán perdió la oportunidad de tener un Estado soberano.

Cuatro hombres llegan a la casa de Mem para llevarlo al Gran Hombre, pero no tienen claro cuál es su casa, golpean donde una mujer que los envía a la casa de un 
anciano, pero tampoco es ahí. Así duran cuatro días llevándolo a distintos lugares de la isla, pero no encuentran al Gran Hombre. Entonces Mem lleva a la casa vecina las pocas copias manuscritas que hizo por encargo, mientras cuatro hombres están acurrucados en un muro cercano vigilando. Dicen que ya deben irse porque se cumplió el contrato. Mem abre la puerta de esa casa y salen muchas aves. La vivienda no tiene habitantes, pero sí sus posesiones. Los cuatro hombres, al ver volar las aves, se van.

La segunda parte de la novela se centra en Qamishli, cuando Mem tenía 21 años, y difiere de la primera parte, puesto que acá Mem muere ahogado en un río casi seco que separa Siria de Turquía. Se hace el velorio en casa. Dino reconoce que había soñado las noches anteriores que Mem se encontraba en Chipre y que quería que Dino se casara con la mujer de las botas de hombre, vecina del barrio.

Luego la novela tiene un giro fantástico en el que Mem, ya muerto, se le aparece a Dino en la noche, y le cuenta que en realidad la de los zapatos de soldado estuvo enamorada de su padre, Hamdi, porque él la cortejó con telas. Habían acordado verse en Kurdistán. Sin embargo, la de los zapatos de soldado no quiso cumplir su parte y se lo dijo a Hifín, hermana de Mem y Dino, quien hizo creer a su padre que Mem preparaba su muerte. Mem sí estaba confabulando para irse con la de los zapatos de soldado y finalmente, dado que su padre no quería hablar con él, nadó por el río que sirve de frontera hasta la parte turca donde murió ahogado.

\section{Sherko Fatah, Tierra de frontera}

Sherko Fatah nació en Berlín en 1964, hijo de madre alemana y padre kurdo-iraquí. En 1975 se trasladó a Alemania Occidental. En 2001 su novela Tierra de frontera recibió el Premio Aspekte al mejor debut literario en lengua alemana. En esta novela Fatah quiso hablar sobre la experiencia de los kurdos que viven una frontera casi imaginaria entre Irak, Irán y Turquía. "No me interesaba la cercanía con el lector, no quería hacer entretenimiento, sino reflejar el dolor, la soledad y el miedo de esa sociedad”, explicó Fatah en entrevista al diario El País (2009) de España. Es así que Fatah se asume como escritor testigo; está dentro de aquellos escritores que Ernesto Sabato reconoce como quienes cuentan a través de sus textos, en oposición a la literatura producida como entretenimiento en serie. Los escritores testigos son "aquellos que sienten la necesidad oscura pero obsesiva de testimoniar su drama, su desdicha, su soledad. Son los testigos, los mártires de una época” (Sabato, 2011, p. 81).

Tierra de frontera (2003) fue publicada originalmente en 2001. La acción sucede en Solimania, ciudad del Kurdistán iraquí, al norte del país, durante un periodo de posguerra entre 1998 y 2001, después de una continua intervención militar de Estados 
Unidos, Inglaterra y Francia, en la que atacaban al ejército iraquí, con el objetivo de hacer cumplir las zonas de prohibición de vuelos entre el norte y el sur iraquí, luego del fin de la Guerra del Golfo (1991), para proteger al Kurdistán iraquí y al sur chiita.

El protagonista es un contrabandista, esposo y padre de tres hijos, quien antes de la guerra era comerciante, pero después de esta se dedicó al contrabando, dada la falta de mercancía por la vigencia del embargo internacional. Para ejercer su función atraviesa continuamente a rastras un sendero que solo él conoce fielmente por las montañas fronterizas entre Irak y Turquía, las cuales están extremadamente minadas. En la primera provincia turca después de la frontera, su cuñado, Zarik, lo provee de mercancía (licor, computadores portátiles y cigarrillos) para llevar a Irak.

En sus viajes el contrabandista conoce a Beno, un militar que luchó en la guerra contra Estados Unidos y Europa. Beno se convierte en el representante del poder estatal frente al contrabandista. Está buscando información acerca de unos bandidos que han asesinado campesinos en la frontera. Beno le indica al contrabandista que cuide a su hijo de 13 años porque tiene amistades indebidas, ya que la escuela donde estudia es patrocinada por Irán.

Este hijo es apresado por el gobierno iraquí y el contrabandista emprende un periplo por la Casa Roja y las jerarquías del poder penal y militar en busca de su hijo. Sin embargo, no da resultado. En un nuevo viaje a Turquía se hospeda en la casa de su hermana y su cuñado por cuatro días, luego vuelve al sendero y es torturado por militares turcos. Se recupera en casa de su hermana hasta que emprende otra vez el camino, pero en el sendero observa que Solimania ha sido bombardeada y se está quemando, el sendero se empieza a llenar de animales y el contrabandista muere alucinando que ve a su hijo, quien realmente había muerto hace más de un año según la información oficial.

\section{Hassan Blasim, El loco de la plaza Libertad}

Hassan Blasim es poeta, cineasta y cuentista iraquí, nacido en Bagdad en 1973. Hijo de un padre militar maltratador y de una mujer analfabeta, creció con sus ocho hermanos en medio de las bombas de la guerra entre Irak e Irán (1980-1988). En Bagdad estudió en la Academia de las Artes Cinematográficas y ganó premios en el Academy's Festival Award for Best Work: Gardenia, como guionista, y White Clay, como guionista y director. En 1998 abandonó Bagdad y se radicó en Solimania, en el Kurdistán iraquí, debido al acoso de la policía secreta de Sadam Huseín. Allí siguió haciendo películas con el pseudónimo de Ouazad Osman. Sin embargo, debido a que en sus películas y ensayos denuncia el ensañamiento de la dictadura de Huseín contra los kurdos, emigró 
nuevamente para no poner en peligro a su familia que vivía en Bagdad. En 2004 se fue para Finlandia, donde ha grabado varias películas y documentales. Ese viaje duró tres años y medio en los que fue torturado y devuelto en varias ocasiones a su lugar de origen.

El loco de la plaza Libertad (2016) es el primer libro de relatos de Hassan Blasim, publicado por primera vez en 2009. Consta de once cuentos centrados en la invasión de Irak de 2003 por parte de Estados Unidos. Allí Blasim narra la experiencia violenta que han afrontado los iraquís debido a la dictadura de Sadam Huseín, a su derrocamiento y luego a la crisis de poder en la que se alternaron el mando el Estado Islámico, la milicia kurda peshmerga (el que camina frente a la muerte) y las fuerzas militares estadounidenses. Para el caso de este artículo se presta especial interés a los cuentos “Lo que pasó y lo que consta” y “La exposición de cadáveres”, puesto que entre los dos hay conexiones intertextuales que tienen como eje el tema del terrorismo.

En el cuento "Lo que pasó y lo que consta" un hombre narra a la inmigración finlandesa su experiencia dentro de la invasión de Irak. Cuenta que como conductor de ambulancia en 2006 recogió las cabezas de seis cuerpos tiradas a la orilla del río Tigris, en Bagdad. Cuando llegó al puente de los Mártires, un coche de policía con cuatro hombres enmascarados y uniforme del cuerpo especial de policía sacaron las cabezas del vehículo y lo secuestraron. El primer grupo de secuestradores que lo tuvo estaba en una casa de los barrios antiguos de Bagdad. "De la pared colgaba una tela negra con unos versos del Corán donde se instaba a los musulmanes a luchar en la Yihad" (Blasim, 2016, p. 14). Luego preparan la escena para grabar con las seis cabezas:

Yo decía, leyendo del papel, que era un oficial del ejército iraquí y que aquéllas eran las cabezas de otros oficiales; con quienes junto a mis compañeros yo había asaltado casas, violado mujeres y torturado a civiles inocentes; que habíamos recibido órdenes de matar un oficial de alto grado del ejército estadounidense a cambio de importantes compensaciones financieras. (p.15)

El hombre pasó durante un año y medio de secuestro por tres grupos, los cuales grababan videos con él para hacerlo pasar por traidor kurdo, cristiano infiel, terrorista saudí, agente de la inteligencia baazista siria o miembro de la Guardia Revolucionaria del Irán del zoroastrismo. En las grabaciones asesinaba, violaba, prendía fuego, ponía bombas y perpetraba crímenes. Las grabaciones se emitían en televisión por todo el mundo. En el cuento aparecen dos personajes, el profesor y el cámara, quienes dominan veladamente las acciones violentas. El profesor es el responsable de las ambulancias del departamento de urgencias, y tiene una concepción fundamentada 
acerca de la trascendencia social del terrorismo y sus lazos con el poder y la fe. Por su parte, el cámara es el camarógrafo que graba con los tres grupos de secuestradores los distintos videos e incluso crea escenas nuevas asignando roles políticamente contradictorios, manipulando el terror televisado.

En “La exposición de cadáveres”, un hombre está haciendo una inducción a un nuevo artista asesino en la organización. Busca que sus asesinos hagan obras de arte terrorista, como exponer en medio de una calle transitada los cuerpos de una madre y un bebé muertos pero que parecen vivos. El hombre de la organización narra la historia del Clavo, quien planeó una exposición de un cadáver en un restaurante. Sin embargo, no la logró porque el cuerpo lo adquirió en la morgue y el encargado de esta lo torturó y asesinó para hacer una obra de arte terrorista con su piel. Este encargado de la inducción se vincula con el discurso del profesor del cuento "Lo que pasó y lo que consta”, puesto que también aclara que el mundo está interconectado de diferentes maneras e igualmente ha construido una concepción del terrorismo que supera la intimidación violenta para ubicarlo como una herramienta usada por hombres poderosos que superan cualquier adscripción a instituciones políticas particulares.

\section{Cultura kurda}

El sociólogo francés Pierre Bourdieu (2000), en la teoría de los campos, entiende que en la sociedad existen leyes generales de funcionamiento susceptibles de análisis sin importar las características individuales de los sujetos. Para Bourdieu el mundo social es determinado por "estructuras objetivas, independientes de la conciencia y de la voluntad de los agentes, que son capaces de orientar o de coaccionar sus prácticas o sus representaciones” (p. 127). La teoría de Bourdieu es de corte marxista, es decir, tiene un enfoque estructural y constructivista desde el cual se tiene la premisa de que la sociedad está dividida en clases y que las relaciones de clase están inmersas en la lucha. Sin embargo, Bourdieu también encuentra que las clases sociales, además de responder a una base económica, tienen base en un sistema simbólico que es determinante en las relaciones de poder.

El sistema simbólico se legítima cuando la sociedad en su conjunto lo reconoce y lo acepta, por ejemplo, cuando en la novela Las plumas, Hamdi, el padre de Mem, y sus amigos evitan hablar en público la lengua kurda, puesto que la sociedad siria en su diversidad lingüística naturalizó esa censura. En esta prohibición se expresan relaciones de poder en las que los kurdos históricamente han sido 
sometidos. Aunque hoy en día las milicias $\mathrm{YPG}^{1}$ (Unidades de Protección Popular) y $\mathrm{YPJ}^{2}$ (Unidades de Protección Femeninas) han logrado avances hacia la consolidación de su modelo socioeconómico, el Confederalismo Democrático (Albani, 2016), el cual incluye el uso libre del kurdo en el Kurdistán sirio.

El campo, el habitus y el capital son los principales conceptos que Bourdieu trabaja para delimitar los escenarios de las prácticas sociales y para identificar relaciones entre la economía, lo simbólico y el poder.

El campo es una estructura social estructurante, conformada por instituciones, agentes y prácticas. Es estructurante porque tiene normas explícitas e implícitas que dan sentido a las relaciones entre los agentes (las prácticas). La visión del mundo que el agente construye en la socialización dentro del campo está coaccionada por la estructura de ese campo (económica y simbólica), el agente a su vez reproduce y alimenta la estructura del campo donde está inmerso (Bourdieu, 2000), de acuerdo con la transformación de su habitus.

En síntesis, los campos son los espacios de estructuración y articulación de las colectividades. Por tanto, existen numerosos campos (el campo político, el campo religioso, el campo artístico, el campo educativo, etc.) en donde están inscritos los agentes según sus intereses y el impacto que tienen los campos sobre sus vidas. Los sujetos que forman parte del campo están dotados del habitus, lo que implica conocer las leyes inmanentes al campo de interacción.

En cada campo existe una confluencia de capitales (económico, cultural, social y simbólico) y de luchas por la apropiación de estos. De acuerdo con su evolución histórica cada campo establece roles, jerarquías, formas de participación y confrontación de individuos y colectividades. La disparidad entre agentes para participar activamente en el campo refleja una condición de búsqueda de poder.

1 Las YPG (Unidades de Protección Popular) fueron creadas en 2004 por jóvenes kurdos sirios. Empezaron a aparecer en la escena militar en 2011, en el inicio de la Guerra Civil Siria. Forman parte de la milicia kurda siria. Lideran las Fuerzas Democráticas Sirias (FDS), una alianza kurdoárabe que lucha contra el Estado Islámico en Siria, con el respaldo de Estados Unidos. Cuentan aproximadamente con 65000 combatientes y se considera que son el brazo armado del Partido de la Unión Democrática (PYD), el cual conforma la principal agrupación política kurda en Siria (Albani, 2016).

2 Las YPJ (Unidades de Protección Femeninas) fueron creadas por mujeres kurdas en 2014 y se unieron a las YPG, para contener la intromisión de la Guerra Civil Siria en el Kurdistán sirio. Combaten al Estado Islámico. Conforman parte del brazo del PYD (Albani, 2016). 
El concepto de capital hace referencia a un valor social que se busca apropiar o tener en mayor medida dentro de un campo, o entre campos. Por ejemplo, el capital económico trasciende los distintos campos, mientras que el capital cultural del conocimiento de la numismática solo tendrá trascendencia entre expertos y coleccionistas. Los principales capitales son el económico (dinero, propiedades, inversiones, etc.), el social (relaciones, contactos, membresías, parentescos, etc.) y el cultural (saberes, conocimiento socialmente válido, títulos académicos, etc.).

El habitus, que es producido dentro de los campos, es definido por Bourdieu (1991a) como:

Los acondicionamientos asociados a una clase particular de condiciones de existencia [...], sistemas de disposiciones duraderas y transferibles, estructuras estructuradas predispuestas para funcionar como estructuras estructurantes, es decir, como principios generadores y organizadores de prácticas y representaciones que pueden estar objetivamente adaptadas a su fin sin suponer la búsqueda consciente de fines y el dominio expreso de las operaciones necesarias para alcanzarlos, objetivamente "reguladas" y "regulares" sin ser el producto de la obediencia a reglas, y, además, colectivamente orquestadas sin ser producto de la acción organizadora de un director de orquesta. (p. 92)

El habitus produce en los individuos percepciones, valoraciones y acciones que generan categorías de la realidad, es decir, el principio de distinción en el que los agentes clasifican su entorno y en este proceso se clasifican a sí mismos, identificando su posición social ligada a su grupo de pertenencia, la cual los distingue de otras colectividades. El acceso desigual a los diferentes tipos de capital (condiciones sociales, los recursos económicos y culturales disponibles, la experiencia vital, las relaciones con las instituciones y con otras personas) hace que los sujetos sientan identidad dentro de su grupo o clase específicos, frente a otros grupos sociales. Es la lógica de la diferenciación que se dirige hacia prácticas de las cuales el sujeto no es plenamente consciente, aunque sea libre de tomar decisiones.

El habitus es un sistema de predisposiciones hacia la acción; por tanto, las acciones que se realizan forman un conjunto coherente. Es duradero y transferible: duradero porque puede permanecer en una cultura así cambien sus condiciones, y transferible porque puede permanecer en diferentes campos, como la familia y las amistades.

Para estudiar el habitus en un grupo social se debe interpretar en las prácticas de los actores sus posiciones sociales, y no el sentido explícito que le atribuyen a sus 
acciones. Se debe entender el sentido que subyace en la acción, el cual expresa jerarquías y conflictos sociales. Las acciones o prácticas expresan una adecuación entre medios y fines desde la perspectiva del agente. Martínez (2017) sintetiza la teoría de Bourdieu con la fórmula: [(habitus) (capital) $]+$ campo = práctica.

\section{Relación entre mujeres y hombres}

En las obras estudiadas en este artículo es muy diciente cómo el rol tradicional de la mujer en la cultura kurda ha sido el de ama de casa, sobre la cual algunas veces se ejerce violencia física o simplemente no se la consulta para asuntos que corresponden a campos sociales distintos al hogar. El rol de la mujer se suele limitar a su papel en la procreación del hogar y en el cuidado de los hijos. Con ello se demuestra un habitus marcado por la tensión social entre dominadores y dominados, en el que los kurdos suelen estar dominados en sus sociedades, y, por tanto, en el hogar reproducen la dominación pasándola a las relaciones de género.

En el cuento "El mercado de historias" (Blasim, 2016), Hamrani, un escritor de Bagdad, en busca de inspiración para sus historias, observa a una mujer a la que se le caen las naranjas en la calle, el contexto es el Bagdad de la invasión estadounidense de 2003:

Es cierto que al principio pensó que la mujer era una terrorista que se iba a inmolar en el mercado, una idea que se aloja en el lector y suscita su curiosidad, sobre todo porque para muchos hombres, en el fondo, una mujer no es más que un coño, un culo y un par de tetas: un trozo de carne apetitoso, concebido para follar y cocinar. El hecho de que sea una suicida es una ofensa para su hombría, aunque pensar en la carne desgarrada de una mujer podía servirles como chascarrillo para poner la polla en acción. (p. 69)

En este ejemplo se observa cómo el valor que suelen dar los hombres a la mujer está sexualizado y luego supeditado al campo familiar. Esto además apoyado en el islam, el cual la mayoría de los kurdos profesa en la variante sunnita, aunque también existen alevíes, chiitas, zoroastrianos, yezidíes y cristianos (Albani, 2016). La comandante del $\mathrm{PKK}^{3}$ (Partido de los Trabajadores de Kurdistán, de origen turco)

3 El PKK (Partido de los Trabajadores de Kurdistán) es un partido político fundado en Turquía en 1978. El cual lucha por la independencia de Kurdistán en Turquía, Siria, Irak e Irán. Su presidente, Abdullah Öcalan, está condenado a cadena perpetua en Turquía desde 1999 por terrorismo y separatismo (Albani, 2016). 
Rengin decía en 2013 que en la sociedad kurda "la mujer de la casa es el orgullo de la familia, pero ese orgullo pasa entre sus piernas” (Albani, 2016, p. 27). Por su parte Abdullah Öcalan, presidente del PKK, entiende que la destrucción del ámbito rural, donde había residuos de la sociedad matriarcal, por el empoderamiento del hábitat urbano ha facilitado la "consolidación del patriarcado y de estructuras de poder antinaturales, como son el Estado o la religión entendida como instrumento de dominación cultural, sea esta musulmana, cristiana o yezidi” (Martorell, 2016, p. 116). Se observa, entonces, cómo la relación patriarcal machista entre hombres y mujeres se corresponde con la violencia simbólica que aplican las instituciones gubernamentales y religiosas que dominan las relaciones del poder social.

En el cuento "La bolsa de Ali", se expresa la violencia ejercida sobre la madre como si esta fuera un recipiente de la frustración social de los hombres (padre, hijos):

Su padre era vigilante nocturno en varias tiendas del centro y su madre, como la mayor parte de las madres iraquíes, era una criatura en la que se volcaba todo el fango de la injusticia, la tristeza y la brutalidad humana. Era víctima de un mundo depravado de hombres, sin esperanza de remisión. Si uno pudiera vivir en sus carnes lo que experimenta una madre iraquí en un solo día de su vida, no sería difícil olvidar que Dios existe. Éste puede parecer un sentimiento romántico, simple e ingenuo, pero si hubiera cámaras ocultas que mostraran al mundo todos los horrores que padece una mujer iraquí en su propia casa, hasta las piedras alzarían la voz para denunciar el estado de las cosas y maldecir a los causantes. Los hermanos de Ali habían heredado de su padre la inclinación a echar sobre su madre todos los problemas y desgracias de la pobreza y del destino. La apaleaban por la razón más nimia, y ella reprochaba al Señor el que no le hubiera dado una hija que la ayudara con las tareas de la casa y se apiadara de ella. (Blasim, 2016, pp. 78-79)

La madre de Ali ha interiorizado tanto en su habitus su rol subordinado en la jerarquía familiar, que ella misma lamenta no tener una hija para compartir la carga de las labores del hogar. De acuerdo con Bourdieu (2000), las relaciones entre y dentro de las clases sociales se dan a nivel económico y simbólico. Por tanto, es habitual que se reproduzca continuamente en la interioridad de los agentes la exterioridad de las prácticas sociales, $\mathrm{y}$, a su vez, que se reproduzcan formas de exteriorización de las subjetividades (Ansart, 1992), tal como ocurre en este caso, en el que la madre de Ali no cuestiona la agresión que se ejerce sobre ella, sino que, por el contrario, quisiera que se reprodujera en otra mujer, una hija, y así compartir el peso de la jerarquía familiar. 
Es diferente el rol cultural que tiene Iraz, la mujer con la que comparte celda, hacia 1933 en Çukurova, Hatçe, la novia de Memed. Iraz y Hatçe hacen equipo para tejer calcetines donde "aparecían todas sus penas. Ellas no utilizaban modelos ni nada parecido, sino que creaban los dibujos de colores tan amargos como el veneno" (Kemal, 1997, p.183). Incluso, en los combates que tiene Mem, Iraz le sirve como compañera, tomando el fusil. Acá tenemos una mujer representante de una sociedad más rural, matriarcal, que poco a poco se va perdiendo en el siglo xx por el crecimiento urbano y la persecución de los Estados a las aldeas kurdas.

Sin embargo, la constante urbana en estas obras literarias, en la relación de poder que se da en las familias, entre hombres y mujeres, consiste en que ellas desempeñan función de cuidadoras de los hijos y amas de casa, mientras que el hombre provee al hogar asumiendo riesgos al recurrir a una economía ilegal de subsistencia en sociedades que cercan a los kurdos económicamente. Cuando pasa un año sin tener noticias acerca de la desaparición de su hijo, el contrabandista de Tierra de frontera se desespera, y abandona a su esposa y a sus hijos. No puede soportar esa esfera familiar dominada por la resignación de su esposa:

Porque había permitido que surgiera aquella distancia. En su figura, eternamente plegada, y en sus quehaceres podía reconocer día a día los amagos, si no los olvidos, sí una reconciliación con el destino. Aún tenía dos hijos y la casa y todas las tareas las desempeñaba, según le parecía a él, con mayor atención que antes. (Fatah, 2003, p. 143)

La madre tiene una conexión estable con su hogar que le sostiene en la adversidad; debe proseguir con el cuidado diario de su familia. Sin embargo, el contrabandista que vive en los campos públicos del comercio, que tiene un capital social desarrollado, no puede estar conforme aceptando la pérdida de un hijo. Su habitus lo invita a utilizar su capital social para luchar por el rescate del muchacho, mientras que la relación de poder que tiene con su esposa no le permite verla como compañera, sino como una subordinada que no lo puede apoyar efectivamente.

\section{Presencia inminente de la tragedia}

Dentro del habitus de los personajes literarios kurdos subyace una velada conciencia de estar en continuo peligro dentro de sus propias sociedades, lo que los lleva a asumir riesgos como ejercer el contrabando o a sentir una desazón difusa en su cotidianidad. Esta particularidad cultural se basa en la larga historia de lucha y supervivencia a la que se ha sometido la etnia kurda. La presencia de la tragedia sobre los kurdos es una 
especie de capital cultural. Mem (el joven que conquistó la realidad), hijo de Hemdi Azad, vendedor de tela, mientras reflexiona acerca de su decisión de suicidarse, empieza a sentir pesadumbre. La describe de esta manera:

Tanto me deprimí que lloré a lágrima viva, mas conseguí detener el llanto tozudamente porque no estaba acostumbrado de antes a llorar, sino a destruir lo que me rodea o destruirme yo. ¿Qué me pasó en aquel momento? ¿Estaría ocurriendo en alguna parte una catástrofe que yo fuera incapaz de detener? Una catástrofe en cada sitio y a mí no me autorizan ni por un segundo a tener memoria propia de algo semejante. Es la sabiduría de la supervivencia, que no permite que absolutamente todo ocurra en el mismo lugar, a la vez, sino que lo reparte bien, de modo aceptable, dejando que los corazones pusilánimes conserven su debilidad para siempre y los fuertes, su fortaleza eternamente. (Barakat, 1992, p. 22)

Mem está en Chipre, su misión es encontrarse con el Gran Hombre para liberar a Kurdistán. Es consciente de que en esta gran región ocurren catástrofes de forma continua que la memoria no puede retener absolutamente para sobrevivir. Percibe la tragedia que se ha cernido sobre los kurdos incluso en el mismo aire. Cuando a sus 21 años su padre está listo para decidir su destino:

[...] independientemente de que se daba cuenta de la ruina que percibíamos día a día en desazonador silencio. Nunca hablaba de aquel runrún en el que se precipitaba y al que nos arrastraba como dejando que aspirásemos con ávida nariz el viento de sangre que llegaba de Kurdistán. Todo se hacía añicos. Terribles connivencias contra un pueblo que intentaba crear un lugar acogedor para sus vacas, sus cabras, su nostalgia e incluso sus cadáveres. (Barakat, 1992, p. 34)

El padre de Mem se reúne por las tardes a hablar con sus amigos de la historia de Kurdistán, buscando unidad entre provincias kurdas que jamás han estado juntas. Esto marca su carácter: "Siempre estaba malhumorado, como si obstaculizásemos su forma de conjurar la catástrofe. La propia impotencia de hacer algo agravaba su excitación” (Barakat, 1992, p. 35).

Por su parte, el contrabandista de Tierra de fronteras (Fatah, 2003), en el cambio de siglo siente que el margen de acción segura que le permiten los gobiernos en la frontera entre Irak y Turquía no es para él. Prefiere ser contrabandista y asumir los riesgos que se le imponen a los kurdos a través de una frontera totalmente minada como testimonio de la abierta hostilidad que ejerce Turquía sobre Kurdistán desde 1923, cuando Kemal Atatürk eliminó la posibilidad independentista kurda, al excluir 
el artículo 11 de la constitución de la nueva república unitaria turca, que permitía la descentralización provincial. “A partir de ese momento, las palabras 'kurdo' y 'Kurdistán' no solamente desaparecen de libros, periódicos y nomenclaturas urbanas, sino que es prohibida incluso su pronunciación en público” (Martorell, 2016, p. 46).

El contrabandista prefiere seguir su propio sendero, al margen del contrabando permitido por Turquía, "trabajaba por su cuenta y corría, a cambio, el riesgo de estar totalmente solo en la tierra de nadie. Aquello le seducía” (Fatah, 2003, p. 76). La posibilidad que tiene el contrabandista de colonizar por lo menos un sendero oculto entre las fronteras, donde con minuciosidad debe excavar minas, moverlas y enterrarlas, como si abriera y cerrara una cremallera sobre la tierra, reivindica su derecho a tener dominio sobre una tierra, aunque esto lo lleva a la muerte. "Encontrar y utilizar aquellos agujeros, aquellos escondrijos, ésa era su actividad, aunque, con el tiempo, también se había convertido en su pasión” (p. 157).

\section{Economía}

Los grupos dominantes, basados en su mayor acumulación de capital económico, social y cultural, procuran imponer un orden social acorde con su visión de mundo como referente del resto de la sociedad. Esta capacidad de objetivar el capital por parte de los agentes que por contingencias históricas están ubicados en una mejor posición social hace que ejerzan un poder simbólico en sus respectivos campos, influyendo en el espacio y el tiempo de los demás sujetos que están por debajo de su jerarquía, y, por tanto, generando percepciones, valoraciones y acciones.

Este es el caso del poder que ejercen Turquía, Siria, Irán e Irak sobre los personajes de las obras estudiadas, coartando, a partir de la imposición de condiciones económicas precarias, el margen de acción de los kurdos y supeditándolos a los agentes que representan la autoridad nacional.

En El halcón (Kemal, 1997), se retrata el estado premoderno en el que vivía la aldea de Dikenli, al sureste de Turquía:

Dikenli es una de estas llanuras. Acoge cinco aldeas cuyos habitantes no poseen tierras. Toda la tierra es de Abdi agá. La llanura Dikenli es un mundo aparte, con sus propias leyes, con sus propias costumbres. La gente de Dikenli casi no conoce ningún otro lugar más allá de su aldea. Son muy pocos lo que han salido de la llanura. Por otra parte, nadie tiene ninguna noticia de las aldeas de Dikenli, de su gente, de cómo viven. Incluso el recaudador de impuestos sólo para allí cada dos o tres años. Tampoco él trata con los campesinos, no le interesa, visita a Abdi agá y se va. (p. 10) 
Tras la Primera Guerra Mundial el nuevo gobierno turco intentó eliminar a los pequeños señores feudales, los agás, cuyo poder era infinito. De hecho, era un sistema que ya llevaba años tambaleándose. La mayoría de ellos luchó por conseguir tierras. Lo lograron recurriendo a todos los medios para arrebatar la tierra a la gente pobre: algunos por vía legal; otros, mediante sobornos; $y$ otros, mediante la fuerza, a través de la financiación de bandoleros.

El inmenso poder que tiene Abdi agá configura límites de acción para los habitantes de la aldea, límites que han sido interiorizados, provocando conformismo y miedo en la mayoría de los aldeanos. La mamá de Memed representa este sometimiento. Cuando Memed le propone marcharse con él y Hatçe para la ciudad de Çukurova y escapar del poder del agá, ella responde: “No voy a dejar mi tierra ni mi hogar y no voy a ir a ningún sitio. Tú llévate a Hatçe y vete. Pero te vuelvo a decir, hijo, que estás solo. De esto no va a salir nada bueno” (Kemal, 1997, p. 79).

No obstante, en Tierra de frontera, cuyo contexto es la década de los años noventa del siglo xx, en la frontera entre Irak y Turquía, se observa que en la región del Kurdistán turco ya no se respeta a priori la propiedad de la tierra heredada desde los tiempos de los agás. Un comerciante turco que le debe dinero al contrabandista ha sido atacado por campesinos encapuchados que lo golpearon porque exigía la tenencia de sus tierras por escrituras, así no las utilizara. El contrabandista está a favor de los campesinos, y le responde al comerciante turco:

Los campesinos son todos iguales en esta región, da igual que sean de aquí o de allá. Las tierras de cultivo pertenecen a aquel que vive de ellas. Siempre fue así. No van a dejar una superficie intacta sólo porque pueda pertenecer a algún otro que no está allí. Tendrías que haberte acercado a ellos y negociar.

—No, no — resopló el hombre—, no tienen derecho a mis tierras ni a mi tiempo. Yo no tengo qué negociar. [...] Les he dicho que si no reconocen lo que tengo por escrito, volveré con hombres armados. Y es lo que pienso hacer. (Fatah, 2003, pp. 138-139)

Mientras el habitus del comerciante lo ubica en una posición de poder, de terrateniente, los campesinos kurdos de Turquía han avanzado en su derecho a utilizar las tierras que han habitado por generaciones, demostrando que transitan el camino de la reivindicación de derechos.

En Las plumas (Barakat, 1992), Hamdi como comerciante de telas kurdo no tiene permiso para importar su materia prima, por eso se ve en la necesidad de traerla de contrabando, lo cual es muy significativo puesto que el territorio de Kurdistán 
perteneció a la Ruta de la Seda que conectaba comercialmente desde el siglo I a. C. a Asia con África y Europa. No obstante, el recorrido que debe hacer la tela de Hamdi es tortuoso y arriesgado:

Hamdi vende al por mayor la tela procedente de Beirut, Alepo y Mosul; pero la mayor parte de esa tela enrollada en una madera poligonal tiene licencia de exportación para propiedad solamente de los clientes de Hamdi, porque atravesó las montañas de Tabriz en Irán, y cruzó los bosques del norte de Siria, y los turcos de Diyarbakir y Adana, con gran precaución y mucho sudor, pasando por estaciones en las que se alteran los rostros que entregan la tela y los que la reciben, hasta llegar a personas influyentes que la esconden en las aldeas dispersas en el norte limítrofe con la frontera turca, y luego es distribuida y repartida a los almacenes de venta al por mayor después de haber llegado a las casas de los dueños de esos almacenes sobre mulas que marchan únicamente de noche, con lentitud, sin espantar a las gallinas ni hacer ladrar a los perros. (pp. 184-185)

Todo el periplo que hace la mercancía de Hamdi equivale al esfuerzo de este personaje por adaptarse a un país (Siria) que es abiertamente hostil hacia los kurdos; aunque a partir de la coyuntura de 2015, cuando las fuerzas Y PG asumieron un rol preponderante en la lucha contra el Estado Islámico, se está constituyendo una región autónoma, Rojava, el Kurdistán sirio. Martorell (2016) explica que tradicionalmente los kurdos en Siria son "verdaderos parias en su propio país hasta el punto que en torno a 300000 majtumín, como se les denomina, ni siquiera tienen reconocida la ciudadanía y carecen de documentos de identidad” (p. 53). Por tanto, esta población no puede acceder a servicios públicos, propiedades y educación.

Ante esta condición ciudadana, el padre de Mem en público acepta las consecuencias, pero en privado urde una esperanza para apoyar la independencia de Kurdistán. Cuando la policía le informa a Hamdi que su mercancía ha sido decomisada, responde: "De todas formas, habría donado ese cargamento al puesto de policía" (p. 199). El habitus que le inculca la sociedad de Qamishli espera de él resignación. Sin embargo, el capital cultural que tiene, de la historia de las numerosas y centenarias revueltas de los kurdos, lo impulsa a buscar alternativas de resistencia.

En Tierra de frontera (Fatah, 2003), tras la Guerra del Golfo, Solimania está cercada comercial y militarmente. Hay un embargo internacional; por tanto, la actividad del contrabandista es muy apreciada. El contrabandista y su sobrino (alter ego de Fatah) se encuentran con los nuevos relojeros en las calles, "mientras los verdaderos relojeros, con motivo del embargo internacional, habían cerrado sus locales 
hacía tiempo, en las aceras había chicos sentados que no tenían intención de vender ningún reloj sino que se habían especializado en su reparación” (p. 17). El sobrino evidencia la limitación de recursos en Solimania, y la importancia de los repuestos de segunda mano para mantener funcionando cualquier maquinaria. "Las personas estaban supeditadas a las existencias. La ciudad pertenecía a los comerciantes, que a su vez, dependían de los contrabandistas” (p. 19).

En El halcón (Kemal, 1997), Las plumas (Barakat, 1992) y Tierra de frontera (Fatah, 2003), la economía de los personajes está en el margen de la subsistencia, debido a las relaciones de poder que en sus sociedades ejercen los Estados. En El halcón sobrevive el feudalismo; en Las plumas la discriminación ciudadana por parte del Estado sirio limita la posibilidad de ascenso social para los kurdos; y en Tierra de frontera se vive una época de desestabilización económica debido a la intervención norteamericana, a los embargos de la onu y al cierre del paso fronterizo turco de la aduana de Habur. Estas relaciones económicas con sus sociedades marginan a los protagonistas, aunque púbicamente adoptan una posición sumisa, de acuerdo con la actitud que el habitus habría de formar en ellos, se van configurando inconformidades que forjan intentos aislados de subvertir el orden para darle un espacio al renacimiento de Kurdistán.

\section{Relación entre los kurdos y los Estados que cruzan Kurdistán}

El rol público que desempeñan los kurdos en sus sociedades se centra en los hombres, quienes deben tranzar una mínima permisividad a sus actividades económicas ilegales con los agentes representantes de los diferentes Estados, los cuales permiten que subsistan a través de actividades peligrosas relacionadas con el contrabando, o los explotan abiertamente, reafirmando las jerarquías sociales. Esto se evidencia a través de discursos y el ejercicio de la fuerza, que generalmente lleva la acción de las novelas y cuentos al escenario de las fronteras políticas entre Turquía, Irak, Irán y Siria, y a los accidentes geográficos más agrestes e inhóspitos; escenografías cargadas de simbolismo, puesto que representan la impotencia que los autores observan ante la imposibilidad de que Kurdistán sea un territorio soberano.

\section{Jerarquización}

En su obra Vigilary castigar (2016), publicada por primera vez en 1975, Michel Foucault desmonta los mecanismos de la microfísica del poder desde la aplicación de la tortura 
en la Edad Media, pasando por el terrorismo moderno, hasta llegar al refinamiento de mecanismos en los que el individuo tiene tan interiorizada la estructura social que él mismo exige que se le respete su rol de dominado en su respectivo Estado.

Este sujeto social requiere de la inserción en el aparato productivo para tener una posición dentro de su sociedad. Así se configura una pertenencia jerárquica en el sistema productivo que la mayoría de personas elige:

Es preciso [...] tener un amo, hallarse inserto y situado en el interior de una jerarquía; no se existe más que estando fijado en relaciones definidas de dominación: “¿En casa de quién trabaja usted? Es decir, puesto que no es usted amo, preciso es que sea servidor, cualesquiera que sean las condiciones; no se trata de la satisfacción de su persona; se trata del orden que hay que mantener”. (Foucault, 2016, p. 340)

Memed, al vivir en un estado feudal, está supeditado al trabajo agrícola en las tierras de Abdi agá. Cuando Süleyman le pregunta cómo es vivir en su tierra, Memed responde: "Hace dos años que trabajo sus tierras. Los cardos me devoran, me muerden, me desgarran las piernas como perros rabiosos. En esas tierras es donde trabajo. Todos los días Abdi agá me mata a golpes” (Kemal, 1997, p. 18). Memed existe en su sociedad en la relación de poder entre Abdi y los campesinos kurdos que habitan la aldea. Dado que las condiciones laborales son similares a la esclavitud, Memed las rechaza y Abdi las reivindica por medio de la violencia física y la violencia simbólica de sus discursos.

Por su parte, Mem y Dino en la Siria de la década de los setenta del siglo xx no pueden formarse profesionalmente para insertarse en el aparato productivo. La sociedad les restringe el ascenso social, negándoles el acceso al capital cultural que da la educación universitaria y, por tanto, al consiguiente capital económico y social que puede forjar una profesión. Cuando terminaron la secundaria "no hallaron suficientes documentos para ingresar en la universidad, pues el padre era de 'nacionalidad incompleta', y eso sólo significa que no tenía nacionalidad. Por eso dejaron de estudiar para trabajar con su padre en el gran almacén de telas” (Fatah, 2003, p. 172). Mem y Dino existen en su sociedad, pero su rol se debe limitar a trabajos no calificados. Este es un resultado de la estratificación que ejerce el Estado sobre ellos.

El contrabandista es un hombre importante en Solimania, puesto que debido a los embargos internacionales él funge como el medio para proveer de mercancías a los hombres ricos, generalmente comerciantes con relaciones en las esferas del Gobierno y militares, lo que lo hacía sentir como parte del grupo de esas personas influyentes, aun cuando lo complejo de sus relaciones le desbordara. Gracias a su 
trabajo logra tener un capital social que le permite buscar a su hijo en la Casa Roja y la cárcel, aunque de forma infructuosa.

El capital que le asigna al contrabandista un lugar relativamente relevante en su sociedad es el conocimiento minucioso (capital cultural) que ha adquirido de las tierras colindantes con la frontera de Turquía, donde tiene un sendero libre de minas. "Sólo él y quizá otros dos más tenían un sendero; ése era su capital. ¿Quién podía estar tan loco como para moverse libremente por allí?” (Fatah, 2003, p. 34). En la asunción de riesgos que pocos asumirían en las montañas fronterizas radica el valor social del contrabandista.

\section{Ejercicio del poder}

Abdi agá como señor feudal de Dikelin representa un sistema económico en el que los campesinos solo tienen como moneda de cambio su trabajo. Foucault (2016) indica que “con el feudalismo, y en una época en que la moneda y la producción están poco desarrolladas, se asistiría a un brusco aumento de los castigos corporales, por ser el cuerpo en la mayoría de los casos el único bien accesible" (p. 34). Este es el caso de Memed y su madre, quienes son sometidos por la fuerza a trabajar para cumplir con la cuota de la cosecha para Abdi agá. Sin embargo, Memed no se quiere sujetar a este sistema económico; en consecuencia, Abdi agá ejerce un sutil castigo corporal sobre su madre y él: solo les deja un cuarto de la cosecha de trigo, lo cual es muy poco para pasar el invierno, cuando normalmente reciben un tercio, lo que los lleva a pasar hambre y a tener que vender, prácticamente regalada, una novilla que representaba su único capital.

Foucault (2016) entiende que el cuerpo está inmerso en un campo político.

"Las relaciones de poder lo convierten en una presa inmediata; lo cercan, lo marcan, lo doman, lo someten a suplicio, lo fuerzan a trabajos, lo obligan a ceremonias, exigen de él signos” (p. 35). El sometimiento político del cuerpo se apoya en su función económica:

El cuerpo, en una buena parte, está imbuido de relaciones de poder y de dominación, como fuerza de producción, pero, en cambio, su constitución como fuerza de trabajo sólo es posible si se halla inmerso en un sistema de sujeción (en el que la necesidad es también un instrumento político cuidadosamente dispuesto, calculado y utilizado). El cuerpo sólo se convierte en fuerza útil cuando es a la vez cuerpo productivo y cuerpo sometido. (Foucault, 2016, p. 35)

Cuando el contrabandista busca acceso a la Casa Roja para indagar por el paradero de su hijo, Beno, un militar iraquí, lo aborda en la calle y le dice que lo puede 
consultar para que mejore su negocio, aunque esa confianza en realidad ocultaba la intención de que le diera permanentemente información sobre la frontera:

En un principio el contrabandista se alegró de haber conseguido al fin la ansiada protección del poder. Más tarde comprendió que aquel papel con el rango, el nombre y el departamento de Beno representaba una especie de prestación de servicio obligatorio para él. Tendría que ir de buena o mala gana a aquel lugar no demasiado agradable, incluso aunque nada especial le llamara la atención. Ellos querían ser informados, aquélla era una de las condiciones hasta ese momento desconocidas de su planificado negocio. (Fatah, 2003, p. 78)

Se observa cómo Beno, representante del Estado iraquí, le permite al contrabandista continuar con su trabajo ilegal, pero solamente porque gracias a este servicio puede dar información acerca de nuevas milicias que se quieren asentar en las montañas fronterizas. De esta manera Beno utiliza la necesidad económica que tiene el contrabandista, además de su preocupación por el destino de su hijo, para condicionarlo a partir de su modus vivendi, en el desarrollo de la dinámica del poder, en la que quienes dominan refrendan permanentemente su posición privilegiada.

Este sometimiento que Beno ejerce sobre el contrabandista es sutil, tanto así que el contrabandista tarda en comprenderlo. Es un sometimiento que apela al control de la fuerza del cuerpo, "este saber y este dominio constituyen lo que podría llamarse la tecnología política del cuerpo" (Foucault, 2016, p. 35).

Desde la lógica de la teoría de Bourdieu (1991b), los grupos dominantes, basados en su mayor acumulación de capital económico, social y cultural, procuran imponer un orden social en concordancia con su visión de mundo como referente del resto de la sociedad. Esta capacidad de objetivar el capital por parte de los agentes que, a través de procesos históricos, están ubicados en una mejor posición social, hace que ejerzan un poder simbólico en sus respectivos campos, influyendo en el espacio y el tiempo de los demás sujetos que están por debajo de su jerarquía, y, por tanto, generando percepciones, valoraciones y acciones.

El político, el militar y el comunicador son agentes revestidos de un poder simbólico que les atribuye sus posiciones en sus respectivos campos, el cual está legitimado por el conocimiento y reconocimiento de los otros. Al monopolizar el poder simbólico también pueden ejercer una violencia simbólica. La materialización del poder simbólico se da en mayor medida a través del lenguaje, de la palabra. Quien tiene el poder para clasificar la realidad a través de las palabras tiene, a su vez, la fuerza para imponer las clasificaciones. 
En Las plumas (Barakat, 1992) el poder ejercido a través de la violencia simbólica se da, en parte, a través de las emisoras, las cuales no hablan de Kurdistán. Hamdi, el padre de Mem, es aficionado a la radio, le gusta deambular por las emisoras. Su hija Hifín y él protagonizan una escena familiar en la que se retrata la violencia simbólica del Estado, al aplicar una censura implícita al tema del Kurdistán. Hamdi busca:

[...] un locutor olvidado entre los numeritos de las emisoras, y [Hifín] se sienta con los muslos pegados al pecho, rodeados con los brazos, exactamente como hace Hamdi. Le interrumpe a cada rato con las mismas palabras, sin añadir ni quitar una sola: “¿Hablan de Kurdistán, padre?”, refiriéndose a los locutores, y el padre responde de modo ininteligible: “Todavía no. Todavía no.” Dino no sabe por qué su hermana hace una pregunta así, siempre la misma, si ella jamás escuchó antes mencionar Kurdistán en las emisoras de su padre. Pero a él le gusta, en cierta forma aquella íntima espera que acompaña la interrogación de su hermana, una espera que soporta Hifín todo aquel día, y quizá durante el sueño también, según cree Dino. (p. 180)

El Estado sirio ejerce aquí su poder simbólico a través de la radio procurando negar la identidad kurda a la población y a su vez imponiéndole su propia identidad árabe.

La censura como violencia simbólica también se extiende al idioma kurdo, el cual ha sido prohibido en Siria. Hamdi suele reunirse con sus amigos en las tardes para tomar el té y rememorar la historia de Kurdistán. En la tertulia su amigo Qádir Hammu le muestra un poema kurdo en secreto. Puesto que "la lengua kurda está prohibida, y Rammu Krif preso en la cárcel de al-Hasaka por haber adquirido libros en kurdo sobre morfología y exégesis, lo denunció su vecino siríaco que milita en las filas del partido que gobierna el país” (Barakat, 1992, p. 194). Quienes transgreden la prohibición de hablar kurdo son trasladados a al-Hasaka, una especie de prisión que garantiza un control más efectivo sobre los kurdos, con el objetivo nacionalista de defender la libertad siria, por medio del control de las minorías étnicas que habitan el país.

No obstante, para los kurdos es fundamental la defensa de lo que le es común a sus integrantes como su lengua, su cultura, sus tradiciones, su folclore, su historia y sus territorios. Aunque existen aspectos culturales y sociales que generan diferencias entre ellos, como los diversos dialectos del idioma kurdo o desigualdades regionales, ser kurdo es una identidad de tipo étnico basada en la tradición familiar, tribal y clánica, así como la creencia generalizada del islam, su pasado común, y, por 
último, la ambición de obtener un territorio propio con soberanía política, denominado Kurdistán (Férez, 2014).

El terrorismo en los cuentos "Lo que pasó y lo que consta" y "La exposición de cadáveres" (Blasim, 2016) tiene un valor fundamental dentro de las prácticas de dominación de los Estados, sobrepasando adscripciones políticas y religiosas en un juego jerárquico en el que las posiciones más altas se difuminan a la vista de los demás miembros de la sociedad. El jefe de urgencias del hospital, el profesor, acude a la fe como medio para cometer actos terroristas:

La superstición y el derramamiento de sangre son la base que sustenta el mundo. El ser humano no es la única criatura que mata por su pan, o por amor, o por el poder. Los animales de la selva también lo hacen, de un modo u otro. Pero el hombre es la única criatura que mata por su fe. [...] el problema de la humanidad sólo se puede resolver mediante el terror constante. (Blasim, 2016, p. 11)

La referencia a la fe se puede extender no solo al campo religioso, sino a la fe en que un gobierno o un Estado representan los intereses de sus ciudadanos. De acuerdo con Foucault (2016), el poder que se ejerce socialmente no es una propiedad en sí de los grupos que tienen dominio sobre otros, sino que es una estrategia que responde a tácticas y técnicas. Por tanto, exige ser refrendado continuamente:

Hay que admitir, en suma, que este poder se ejerce más que se posee, que no es el "privilegio" adquirido o conservado de la clase dominante sino el efecto de conjunto de sus posiciones estratégicas, efecto que manifiesta, y a veces acompaña, la posición de aquellos que son dominados. (Foucault, 2016, p. 36)

La permanencia del poder de la clase dominante se da gracias a la huella que su ejercicio del poder deja en las personas que no lo detentan. Por ello, recurrir a la fe como pilar emocional de los sujetos es una forma de generar un fuerte impacto desestabilizante para el individuo, pero más aún para la sociedad si los atentados terroristas se ejecutan cada día ondeando banderas de diferentes confesiones o gobiernos.

El protagonista de "Lo que pasó y lo que consta" narra su experiencia con los diferentes grupos que lo tuvieron secuestrado: "grababan vídeos conmigo hablando, contando que era un traidor kurdo, un cristiano infiel, un terrorista saudí, un agente de la inteligencia baazista siria o un miembro de la Guardia Revolucionaria del Irán del zoroastrismo" (Blasim, 2016, p. 18). En las grabaciones el personaje asesinaba, violaba, prendía fuegos, ponía bombas, etc. Estos videos se emitían en televisión por todo el mundo, y expertos, periodistas y políticos los discutían. 
El hombre encargado de reclutar asesinos en el cuento "La exposición de cadáveres" (Blasim, 2016) complementa el discurso acerca de la manipulación terrorista, por la cual se ejerce un poder desestabilizador en el Kurdistán que afecta tanto a la población kurda como a los Estados donde esta se encuentra:

Nosotros no somos terroristas cuyo objetivo es cobrarnos la mayor cantidad de víctimas posible con el fin de intimidar a otros, ni tampoco asesinos enloquecidos que trabajan sólo por dinero. Nosotros no tenemos nada que ver con los grupos de fanáticos islamistas ni con la oficina de inteligencia de ciertos gobiernos viles, ni con ninguna tontería por el estilo. Yo sé que ahora mismo usted tiene dudas que le están perturbando, pero ya irá descubriendo que el mundo está organizado en varios niveles, y no es realista creer que todo el mundo va a alcanzar todos esos niveles sin esfuerzo. (p. 58)

Después este hombre invita al nuevo asesino a hacer su mejor esfuerzo por la destrucción del país, Irak: "Todo aquel con el que usted acaba es una obra de arte esperando su toque final. Así podrá usted brillar como una gema en medio de la destrucción de este país” (p. 58).

Balandier (1990) observa que el terrorismo no afecta en gran medida la libertad en países donde los regímenes la limitan fuertemente, su particularidad radica más en los intereses y en los apoyos internacionales que lo mantienen y proveen. "Cualquiera que sea su origen, ideológico y sectario, nacionalista, regionalista, estatal, las corrientes del terrorismo son como las aguas mezcladas. Circulan y se conjugan a favor de las situaciones de crisis, mundiales y nacionales" (p. 196). El terrorismo corroe el poder nacional, y para ello recurre al efecto psicológico sobre la población.

Un atentado terrorista que afecte un país democrático es una oportunidad para aumentar la popularidad del gobierno al mando, y con ello su libertad para ejercer violencia simbólica, si este gobierno propone tratar eficazmente la violencia. "Se desarrolla entonces lo que fue reconocido en Italia como una 'cultura del estado de urgencia', donde los miedos pueden más que las salvaguardas de las libertades” (Balandier, 1990, p. 197). En consecuencia, el terrorismo permite a las democracias dar pasos hacia una especie de totalitarismo solapado.

En los cuentos de Blasim (2016) es patente cómo el terrorismo cumple dentro de los Estados que habitan los kurdos la misión de desestabilizar sus sistemas políticos, de enfrentar entre sí a sus numerosas milicias religiosas o étnicas con el objeto de generar una especie de caos en el cual las potencias mundiales se benefician de la veta que se abre para explotar los recursos energéticos naturales de Kurdistán. 
El terrorismo es una práctica recurrente que se puede corroborar en múltiples momentos de la historia reciente relacionada con Kurdistán, por ejemplo con las denuncias en 2012 del canciller sirio Walid Al Moualmen en la ONU, quien presentó pruebas del apoyo al terrorismo principalmente por parte de Estados Unidos y Francia, las cuales no fueron atendidas; y el ineficaz bombardeo al Estado Islámico en Siria durante la última década por parte de la Coalición Internacional, que tiene como antecedente las invasiones de Afganistán e Irak, que tuvieron como justificación la persecución a terroristas, pero que en realidad fueron "las herramientas para controlar el petróleo y sostener una constante política de desestabilización en Medio Oriente, la cual es impulsada, hasta estos días, por Estados Unidos, Francia y sus aliados” (Albani, 2016, p. 102). En los cuentos de Blasim (2016), el terrorismo contemporáneo encuentra un correlato descarnado que lo evidencia como una táctica dentro de la estrategia que permanentemente busca el dominio de los recursos naturales de Kurdistán.

\section{Subversión como intento independentista}

En las novelas analizadas es constante el desarrollo de personajes que intentan subvertir el orden imperante en sus sociedades, con el objetivo de reivindicar a Kurdistán o, por lo menos, para oponer una resistencia a los agentes encargados de actualizar permanentemente las jerarquías de poder en las que la etnia kurda siempre es relegada. Estos intentos de transformación se dan a nivel individual, puesto que como pueblo los kurdos, a pesar de tener una fuerte identidad y tradiciones comunes, nunca han logrado concretar una organización política plasmada en un Estado propio por diversas razones históricas, como ser parte del Imperio otomano, las traiciones y el desinterés de las potencias después de las guerras mundiales, la creación de Estados modernos en su territorio y la permanente falta de acuerdo entre los dirigentes kurdos en los diferentes espacios del Kurdistán. Estos hechos no han permitido la aparición de un movimiento kurdo lo suficientemente fuerte y uniforme para ser tenido en cuenta por las potencias regionales e internacionales como un actor importante (Férez, 2014).

Deluze y Guattari (2004), en Mil mesetas, exponen la teoría de la línea de fuga a través del análisis de tres novelas. Los autores delimitan tres líneas de influencia sobre los personajes: la línea de segmentaridad dura y bien delimitada, la línea de segmentación molecular, y, por último, la línea de fuga. La primera se compone de muchas palabras, conversaciones, preguntas, respuestas y explicaciones, es decir, es la línea en la que una clase dominante procura permear su manera de clasificar la 
realidad a las demás clases. La segunda línea está hecha de silencios, de alusiones, de insinuaciones rápidas, que se prestan a la interpretación; trata acerca de la interiorización que el individuo hace de la organización de su sistema social, y cómo en medio de esta asimilación su propia subjetividad puede negociar y disentir de lo que se le está inculcando. La tercera línea (línea de fuga) consiste en un estado de apropiación del personaje de su propio devenir, lo que puede desencadenar "cualquier cosa, brizna de hierba, catástrofe o sensación, en una aceptación tranquila de lo que sucede en la que ya nada equivale a otra cosa” (p. 202). Las tres líneas interactúan continuamente entre ellas.

La línea de fuga adquiere relevancia en el presente análisis, puesto que su poder sobre los individuos es tal que:

[...] arrastra a la naturaleza, al organismo y al espíritu. Si pensamos que lo organizado hace referencia a la imposición de tal o cual régimen de totalización, de colaboración, de sinergia o integración, la hipótesis de las líneas de fuga sería que siempre hay lugares, situaciones, hechos, experiencias, etc., por donde todo se escapa. (Deleuze, 2007, p. 43)

El impulso que tienen los personajes de las novelas para rebelarse radica tanto en la marginalidad y opresión a la que son sometidos, así como en el sustrato histórico de luchas que ha lidiado el pueblo kurdo a lo largo de su historia milenaria. Esto hace que desde una perspectiva histórica no sea tan fácil asumir el presente como el tiempo en el que se vive el culmen de la evolución histórica del pueblo kurdo, sino como un momento en tensión que estalla en diferentes batallas que pueden reivindicar la autonomía de esta etnia en Kurdistán, tal como está sucediendo en el norte sirio e iraquí.

Memed ha padecido el maltrato y la explotación laboral que ejerce Abdi agá en la aldea. Esto engendra la necesidad de defender su dignidad, su posibilidad de ser libre. Por ello no acepta la degradación que ejerce el bandolero Durdu, quien no contento con golpear y robar a sus víctimas, las hace desnudarse para quedarse con su ropa interior a manera de trofeo y de marca personal. Ante esto Memed reivindica el espacio íntimo de respeto y libertad al que tiene derecho todo ser humano:

Escúchame, hermano, no hay que presionar tanto a la gente. Puedes matarlos, pegarles, pero no asediarlos. A un hombre le resulta más difícil volver a su aldea sin calzoncillos, desnudo, que morir. No hay que hacer eso. No hay que jugar con la gente. Tienen un lugar, un lugar muy pequeño, donde no hay que tocarles. Yo lo sé por Abdi agá. Eso hay que respetarlo y nunca menospreciar al otro. (Kemal, 1997, pp. 139-140) 
Esa línea de fuga, en la cual Memed termina convirtiéndose en un bandolero que lucha por la libertad de su aldea y por el fin del feudalismo, empieza a germinar en la línea de segmentación molecular (Deluze y Guattari, 2004), puesto que allí su impulso rebelde comienza a manifestarse ante las penurias a las que lo somete Abdi agá. Cuando pasa hambre con su madre, porque Abdi castiga su intento de escape a la aldea de Kesme, se hace manifiesta la cercanía de la línea de fuga:

Memed se sentaba en cualquier sitio y no se levantaba de allí hasta la tarde. Apoyaba la cabeza entre las manos y se sumergía en sus pensamientos. Toda su alma, su vitalidad, su odio, su amor, su miedo, su fuerza se concentraban en sus enormes ojos, donde, de vez en cuando, aparecía un brillo punzante como una aguja que se apagaba enseguida. Era un brillo afilado, penetrante, que infundía terror y simulaba al que aparece y se apaga en los ojos del tigre dispuesto a saltar sobre su presa y destrozarla. ¿De dónde venía? Quizás estaba en su naturaleza; aunque es más probable que proviniese de la tortura que había sufrido, de sus problemas, de su aflicción. Este brillo se había aposentado en los ojos de Memed durante el último año, sustituyendo a la chispa de alegría y excitación que antes había en la mirada del niño. (Kemal, 1997, p. 52)

Acá cobran pertinencia las palabras de Deluze y Guattari (2004) cuando explican poéticamente la transformación que vive el individuo en la línea de fuga: "Devenir uno mismo imperceptible, haber deshecho el amor para devenir capaz de amar. Haber deshecho su propio yo para estar por fin solo, y encontrar al verdadero doble en el otro extremo de la línea” (p. 202). Memed anula su pertenencia al sistema feudal; ahora está listo para combatir. Emprende el viaje por esa línea y en el camino sigue siendo despojado de los pocos lazos que pueden limitar su recorrido insurgente: su madre muere en la aldea y su compañera, Hatçe, muere abaleada por defender la vida de su hijo, el pequeño Memed. Este niño será adoptado por Iraz, y, ahora, ya despojado hasta en su afectividad, Memed está listo para ser su doble rebelde, asesinar a Abdi agá y habitar su línea de fuga en los caminos, ya nunca más atado al destino reposado del cultivo rural.

El rechazo a la condición de sometimiento al dominio iraquí, al dominio de la temida Casa Roja, la cual durante la década de los ochenta del siglo xx fue el principal centro de tortura de los militantes kurdos, ocurre en el personaje del muchacho, el hijo del contrabandista. Este joven de trece años de edad en medio de la destrucción del norte de Irak, después de la Guerra del Golfo en la segunda mitad de la década de los noventa del siglo xx, es educado por una escuela coránica financiada por Irán, puesto que en ese periodo las donaciones internacionales soliviantaban las 
necesidades permanentes que vivían los kurdos por la guerra y el embargo internacional (Martorell, 2016). El muchacho no reconoce la validez de la autoridad de la Casa Roja. Así se lo manifiesta a su padre cuando este lo interroga:

— ¿No te das cuentas de que la Seguridad Interior me quería advertir?

-Advertir ¿de qué?

-Posiblemente representéis un peligro para ella.

- Todo musulmán verdadero supone un peligro para los faltos de decisión y los beneficiarios de la fe - había respirado profundamente antes de terminar la frase. La entonación volvió a tener, a oídos del contrabandista, el aire extraño de las frases aprendidas.

$[\ldots]$

Lo que le había llamado la atención en el chico era la apacible firmeza con la que había mantenido sus convicciones. Evidentemente no tenía miedo de la Casa Roja. ¿Cómo era posible, se preguntaba ahora el contrabandista que este niño fuera tan distinto a él y a casi todos? La seguridad que le daba su islam le hacía parecerse a una única persona, a Beno, que era igual de firme en su propósito. (Fatah, 2003, pp. 89-90)

El muchacho y Beno conforman los polos opuestos de la jerarquía social iraquí. Beno es el agente de la dominación, el muchacho es el rebelde que se opone a esa dominación. En un juego dialéctico de los contrarios. "La confusión paradójica de los contrarios tendría su solución - problemática - en la afirmación de que son parte del estado vital de la vida organizándose y ofreciendo a los individuos sus funciones y alternativas” (Balandier, 1988, p. 54). La lucha por el poder es sistemáticamente dinámica, es una tensión entre opuestos que domina el más fuerte mientras tenga la perseverancia para aplicar sus tácticas a su permanentemente actualizada estrategia de dominación. El muchacho paga el precio de la rebelión, vive su línea de fuga, se convierte en un guerrillero que deambula por la frontera, procurando ejercer un control territorial al margen de los gobiernos iraquí y turco. Sin embargo, su rebelión es coartada por la fuerza del gobierno iraquí, que lo retiene, desaparece y después de más de un año lo reporta como muerto.

Deleuze y Guattari (2004) entienden cómo el análisis de las líneas de los personajes pasa por los lineamientos que atraviesan tanto a grupos como a individuos. Es decir, pasa por el reconocimiento del papel que la política ejerce sobre los sujetos. "Pues, antes que el ser, está la política. La práctica no es posterior al establecimiento de los términos y de sus relaciones, sino que participa activamente en el trazado de 
las líneas, afronta los mismos peligros y las mismas variaciones que ellas” (Deleuze y Guattari, 2004, p. 207). La política procura el escenario donde los individuos se forjan y, en ocasiones, trazan líneas de fuga en las que interactúan con ella, y esta vuelve a interactuar con ellos, en un juego de reciprocidades.

Mem ha sido destinado por su padre a ser parte de un proyecto de restablecimiento de Kurdistán. De ahí que su padre haya decidido darle ese nombre:

Me llamó Mem entre las lágrimas mudas que solía derramar por su héroe Mem, a quien el mul-lá Ahmad Jani ${ }^{4}$, el mayor poeta kurdo, no dejó resquicio sin torturar cuando le dieron suplicio por amar a Zin, hasta que los poderosos le hicieron un agujero en cada hombro arrancando la carne y prendieron ahí velas. (Barakat, 1992, p. 34)

Martorell (2016) advierte que Mem-u-Zin es una metáfora sobre las consecuencias que iba a provocar la división interna del pueblo kurdo. "Se podría decir que fue la primera señal de alarma, el primer llamamiento explícito a levantarse del estado de postración en que se encontraba, a evitar que esa fragmentación fuera utilizada por sus enemigos árabes, persas y rums que les acechaban y dividían” (p. 29). El Mem de Las plumas (Barakat, 1992) es el depositario de la esperanza de su padre, Hamdi, quien quiere que la historia de fragmentación del Kurdistán se transforme, y que su hijo sea uno de los llamados a unificar a la nación kurda sin Estado. Esto está en concordancia con la historia de la construcción de la nación y la identidad nacional kurda, la cual es parte de un proceso político nacionalista que ha pretendido fundamentar la toma del poder para crear el soñado Kurdistán. Elementos constitutivos de esta construcción son los discursos políticos de las élites rurales y urbanas, al igual que la historia real e imaginada del pueblo kurdo (Bozarslan, 2003).

Hamdi en su vida pública, como mercader de telas que acepta su "nacionalidad incompleta", trata de mimetizarse y no generar sospechas ante las autoridades. Sin embargo, en privado recrea junto con sus amigos la historia de guerras y conflictos kurdos, albergando la esperanza de que algún día Kurdistán sea un territorio unido. Esta tensión política se refleja en su línea de segmentación molecular: "Siempre estaba malhumorado, como si obstaculizásemos su forma de conjurar la catástrofe. La propia impotencia de hacer algo agravaba su excitación” (Barakat, 1992, p. 34).

4 Mul-lá significa hombre de religión, erudito. El mul-lá Ahmad Jani escribió en 1569 Mem y Zin, epopeya nacional kurda en 2500 dísticos (Martorell, 2016). 
Mem fue enviado a Chipre con una misión confusa. Hamdi le remitió un encargo al Gran Hombre: “Ocúpate de él hasta que lo haga volver” (Barakat, 1992, p. 38):

Es, pues, ésta una etapa corta en la que no se me busca un futuro como el que los padres deciden para sus hijos ya que el mío me puso ante el Gran Hombre con toda confianza, sin más requisito concreto que entrenarme para estar listo para regresar. ¿Por qué me envió para hacerme volver? ¿Preparaba, por ventura, una revuelta contra todos los gobiernos desde Anatolia hasta Armenia para luego devolverme a su Imperio libre? (Barakat, 1992, pp. 38-39)

Hamdi es entonces el personaje que en carne ajena procura ejecutar su línea de fuga. Ha dispuesto toda su esperanza para impulsar a su hijo Mem hacia la unificación de Kurdistán,

[...] como si bastara que Hamdi pusiera en las manos de Mem una aguja y una hebra fuerte de cáñamo, [...] y decirle: ‘¡Vamos! Remienda el aire, hijo’, y el joven echase entonces un remiendo al aire rasgado como una cortina en el horizonte de su padre. (p. 186)

Sin embargo, en el capítulo II, la acción se devuelve seis años, Mem todavía está en Qamishli y su padre hasta ahora está empezando a planear el destino de Mem. No obstante, este no tiene desarrollo porque Mem muere ahogado en el río casi seco que separa a Siria de Turquía.

Esta línea de fuga de Hamdi ni siquiera tiene un desarrollo real, todo quedó en una especie de plano surrealista que se desarrolla en un sueño de Dino, el hermano de Mem. Dino le cuenta a Hamdi después de ver el cadáver de Mem en el hospital: "Vi a Mem dos veces en mis sueños, hace días [...]. 'Estábamos juntos en Chipre'. El muchacho estuvo a punto de sonreír con tristeza, y Hamdi musitó: ‘Chipre?' Creo que he oído alguna vez ese nombre” (Barakat, 1992, p. 253).

Tanto en Las plumas como en Tierra de frontera, Mem y el muchacho, como personajes que tienen la misión de materializar la línea de fuga de la rebeldía kurda, mueren antes de que su subversión rinda fruto. Solamente Memed logra una reivindicación puesto que participa en el fin del feudalismo del sureste turco, dando paso a una etapa histórica en la que Turquía ejerce su rol de dominación a través del aislamiento socioeconómico al Kurdistán turco. No obstante, el capital cultural kurdo porta la historia de milenarias luchas y resurgimientos, conformando, junto con el empoderamiento de las mujeres como defensoras y constructoras sociales, los cimientos sobre los cuales los kurdos han ganado autonomía gubernamental en el Kurdistán iraquí y sirio en los últimos quince años. 


\section{Conclusiones}

La literatura kurda contemporánea aborda, en palabras de Sherko Fatah, “el dolor, la soledad y el miedo" (El País, 2009) de la sociedad kurda. A raíz de una historia de divisiones y luchas por recomponer la unidad kurda en un Estado soberano, lo cual fue negado en la historia reciente con el tratado de Lausana de 1923, cuando el territorio de Kurdistán fue dividido en cuatro países. Esta división es incluso más sólida en el siglo XXI, puesto que los Estados y las potencias mundiales conocen la importancia geoestratégica creciente de este territorio, rico en recursos naturales.

La opresión a la que los países soberanos someten al pueblo kurdo cruza permanentemente las obras literarias kurdas, que reflejan el drama de esta etnia. Esta literatura se constituye, entonces, como un testimonio del dolor y de la lucha por la autonomía; conforma una voz que decanta un anhelo de independencia y libertad para una población sobre la que tradicionalmente se ha ejercido violencia física y simbólica, prohibiéndosele incluso hablar su lengua y negándosele la adscripción a una nacionalidad.

La literatura kurda puede ser estudiada, en otros trabajos, a través de investigaciones comparativas con la literatura latinoamericana que evidencia y reivindica cultural y socialmente a los pueblos autóctonos que fueron sometidos y absorbidos por Estados hegemónicos, como es el caso de la literatura zapatista mexicana del Subcomandante Marcos, cuyos ensayos, discursos y relatos transmiten la cosmovisión y la crítica social de distintos grupos indígenas mexicanos, y dilucidan sus ideas políticas, especialmente el rechazo al neoliberalismo y la globalización. También se puede estudiar comparativamente la literatura kurda con la literatura mapuche, la cual evolucionó interculturalmente, ofreciendo en castellano y mapudungun su experiencia cultural al interactuar con la sociedad chilena de origen español radicada en su territorio.

En las obras literarias estudiadas se encontró que el habitus que configura las prácticas de los kurdos se construye a través de las relaciones de poder, tanto simbólicas como económicas y físicas, que se dan fuera del hogar entre los kurdos y los agentes que representan los Estados; así como en las relaciones de poder que se dan dentro del hogar, en la interacción entre hombres y mujeres. Además, se identificó que este habitus tiene la particularidad de tener una fuerte tendencia hacia las líneas de fuga, de rebeldía, alimentadas por un capital cultural nacional robustecido históricamente por innumerables batallas en las que se ha luchado por alcanzar reivindicaciones territoriales. 
Dentro de este habitus se observa que las relaciones de poder dentro de los hogares kurdos han tenido un correlato en la relación de poder pública de los hombres kurdos en sus sociedades. Mientras en la esfera pública sufren sometimiento - para proveer al hogar asumen riesgos recurriendo a la economía ilegal de subsistencia-, en la familia son ellos quienes reproducen este sometimiento al violentar físicamente o ignorar a sus esposas y madres. Esto se ha profundizado desde la destrucción del ámbito rural del siglo xix, donde había residuos de la sociedad matriarcal por el empoderamiento del hábitat urbano, el cual ha facilitado la consolidación del patriarcado, el Estado y las religiones como herramientas de dominación.

No obstante, la presencia de la tragedia sobre los kurdos también conforma un capital cultural negativo. Dentro del habitus de los personajes literarios subyace una velada conciencia de estar en continuo peligro dentro de sus propias sociedades, lo que los lleva a asumir riesgos como ejercer el contrabando, o a sentir una desazón difusa en su cotidianidad.

En El halcón (Kemal, 1997), Las plumas (Barakat, 1992) y Tierra de frontera (Fatah, 2003), la economía de los personajes está en el margen de la subsistencia, por las relaciones de poder que en sus sociedades ejercen los Estados sobre ellos. La posición económica asumida margina a los protagonistas kurdos; a pesar de que en la esfera pública asumen una posición sumisa, en concordancia con la actitud que el habitus forma en ellos, en la esfera privada desarrollan inconformidades que derivan en intentos independientes de subversión del orden social para crear una oportunidad al renacimiento de Kurdistán.

En cuanto a la relación de poder entre los Estados y los kurdos, se encontró que esta se mantiene en permanente actualización, configurando límites de acción para esta población, los cuales generalmente son interiorizados, provocando conformismo y miedo en la mayoría de las personas. No obstante, aquellos kurdos que sí tienen el capital cultural del conocimiento de su historia milenaria de luchas se relacionan de manera ambigua con sus sociedades; en público aceptan las consecuencias de ser ciudadanos de segunda, muestran el habitus que las sociedades esperan de ellos, pero a nivel privado urden la esperanza de unificar e independizar a su nación.

Los kurdos requieren la inserción en el aparato productivo para tener una posición dentro de sus sociedades. De esta manera se configura una pertenencia jerárquica en el sistema de producción. Sin embargo, como en el caso de Mem y Dino (Barakat, 1992), quienes en la Siria de la década de los setenta del siglo xx no pueden formarse profesionalmente para insertarse en el aparato productivo, los Estados les restringen el ascenso social, negándoles acceso al capital cultural y al consiguiente 
capital económico y social que puede forjar una profesión. De esta forma, los kurdos son acorralados en el sistema jerárquico social y deben recurrir a actividades ilegales como el contrabando, donde se valora el conocimiento (capital cultural) minucioso que se puede tener sobre los peligros de las fronteras.

Entonces la necesidad económica se configura como una herramienta utilizada por los agentes del poder para someter a los kurdos. Este es el caso de Beno, quien utiliza la necesidad económica que tiene el contrabandista y además su preocupación por el destino de su hijo para condicionarlo a partir de su modus vivendi. Por otra parte, las relaciones de poder también se ejercen por medio de la violencia simbólica de los Estados sobre los kurdos: el Estado Sirio a través de la radio censura la identidad kurda y a su vez impone su identidad árabe; además, la violencia simbólica también se extiende a la lengua kurda, la cual ha sido prohibida en el mismo país.

Por su parte, el terrorismo se constituye como otro instrumento de violencia física y simbólica en la relación de poder entre los kurdos y los Estados que tienden sus fronteras sobre Kurdistán. En los cuentos "Lo que pasó y lo que consta” y "La exposición de cadáveres” (Blasim, 2016), el terrorismo es administrado por sujetos, difusos para la mayor parte de la población, que ocupan las posiciones de poder más altas de la sociedad. Ellos utilizan la fe, como pilar emocional de las personas, para ejecutar actos terroristas que crean un efecto desestabilizador en los sistemas políticos, enfrentando entre sí a milicias religiosas o étnicas. En este contexto, donde el caos ha sido configurado intencionalmente, se benefician las potencias mundiales que explotan los recursos energéticos de Kurdistán.

No obstante, en las obras literarias tratadas se manifiesta el impulso de los personajes para rebelarse, el cual radica tanto en su marginalidad y opresión como en el capital cultural conformado por el sustrato histórico de las luchas del pueblo kurdo. Esto hace que desde una perspectiva histórica el presente se asuma como un momento en tensión, al cual se ha sumado desde 2014 el empoderamiento de las mujeres como defensoras y constructoras sociales, actualizando así las relaciones de poder dentro de la cultura kurda, fortaleciéndola e impulsando victorias como la autonomía gubernamental en el Kurdistán iraquí y sirio.

\section{Sobre los autores}

Fredy Alberto Velásquez Barón. Profesional en Estudios Literarios de la Universidad Nacional de Colombia. Magíster en Evaluación y Aseguramiento de la Calidad 
de la Educación de la Universidad Externado de Colombia. Actualmente se desempeña como auxiliar de investigación en el proyecto "El Estado Islámico: catalizador del irredentismo kurdo y la reconstrucción del Medio Oriente”, desarrollado en 2018, y registrado con el código INV-Ees 2087, de la Universidad Militar Nueva Granada (Colombia). Docente de Lengua Castellana en la Secretaría de Educación del Distrito (Bogotá, Colombia). Sus intereses profesionales son la investigación literaria, la investigación educativa y la docencia.

Juan Carlos García Perilla. Politólogo por la Pontificia Universidad Javeriana. Magíster en Seguridad y Defensa Nacionales de la Escuela Superior de Guerra. Docente investigador del Programa de Relaciones Internacionales y Estudios Políticos de la Universidad Militar Nueva Granada, Colombia. Ha publicado los artículos académicos: "Los spoilers del acuerdo de paz en Colombia: el caso del Clan del Golfo" (2020), "La crisis en Libia y sus efectos en la región del Sahel” (2020), “Cambios y continuidades en la organización política Libia. La era Gaddafi y post Gaddafi desde una perspectiva sistémica” (2019).

\section{Referencias}

Albani, L. (2016). Revolución en Kurdistán. Bogotá: La Fogata Editorial-Pajarera Libertaria.

Ansart, P. (1992). Las sociologías contemporáneas. Buenos Aires: Amorrortu.

Barakat, S. (1992). Las plumas: viaje sentimental al Kurdistán. Madrid: Libertarias.

Balandier, G. (1990). El desorden: La teoría del caos y las ciencias sociales. Elogio de la fecundidad del movimiento. Barcelona: Gedisa.

Blasim, H. (2016). El loco de la plaza Libertad. Barcelona: Galaxia Gutenberg.

Bozarslan, H. (2003). Some remarks on the Kurdish Historiographical Discourse in Turkey (1919-1980). En A. Abbas Vali (Ed.), Essays on the origins of Kurdish nationalism (pp. 14-39). Costa Mesa, CA: Mazda Publishers.

Bozarslan, H. (2014). The Kurds and Middle Eastern State of violence: the 1980s and 2010s. Kurdish Studies, 2(1), 4-13.

Bourdieu, P. (1990). Sociología y cultura. Ciudad de México: Consejo Nacional para la Cultura y las Artes.

Bourdieu, P. (1991a). El sentido práctico. Madrid: Taurus.

Bourdieu, P. (1991b). La distinción. Madrid: Taurus.

Bourdieu, P. (2000). Cosas dichas. Barcelona: Gedisa. 
CIA (2019). Mapa de Kurdistán. Wikimedia Commons. https://commons.wikimedia.org/ wiki/File:20190115-kurds-map.png

Deleuze, G. y Guattari, F. (2004). Mil mesetas. Valencia: Pre-Textos.

Deleuze, G. (2007). Dos regímenes de locos. Textos y entrevistas. Valencia: Pre-Textos.

El País. (2003). Sherko Fatah fabula sobre el contrabando en Oriente Próximo. Recuperado de https://elpais.com/diario/2003/11/03/cultura/1067814006_850215.html

Fatah, S. (2003). Tierra de frontera. Madrid: Siruela.

Férez, M. (Comp.). (2014). Estos son los kurdos: análisis de una nación. Ciudad de México: Porrúa.

Foucault, M. (2016). Vigilary castigar. Ciudad de México: Siglo XXI Editores.

Kemal, Y. (1997). El halcón. Barcelona: Tiempos modernos.

Martínez García, J. S. (2017). El habitus. Una revisión analítica. Revista Internacional de Sociología, 75(3): e074. Dor: http://dx.doi.org/10.3989/ris.2017.75.3.15.115

Martorell, M. (2016). Kurdos. Madrid: Catarata.

Sabato, E. (2011). Antes del fin. Santiago del Estero: Seix Barral.

Torres, F. (2011). Fracturas y tensiones entre Oriente Próximo y el sureste europeo: el Kurdistán. Investigaciones Geográficas, 1(55), pp. 135-168. 